\title{
LA CORNALINA EN EL BRONCE FINAL Y LA EDAD DEL HIERRO DEL SUR DE PORTUGAL
}

\author{
THE USE OF CARNELIAN IN THE LATE BRONZE AGE AND IN THE IRON AGE OF SOUTHERN \\ PORTUGAL
}

FRANCISCO B. GOMES

Centro de Arqueologia da Universidade de Lisboa

franciscojbgomes@gmail.com http://orcid.org/0000-0003-0664-6374

Recepción: 22-01-2018

Aceptación: 26-03-2018

\section{Resumen}

En los últimos años el número de elementos de adorno en cornalina documentados en yacimientos del Bronce Final y de la Edad del Hierro en el Sur de Portugal ha aumentado de forma sustancial, y hoy en día se conocen más de cinco decenas de cuentas y colgantes realizados en este material. Se presenta una primera síntesis sobre dichos elementos, con el objetivo de discutir su tipología, cronología y distribución, pero también su eventual origen, que cabría buscar en el Mediterráneo Oriental.

Palabras clave. Cornalina; Adorno; Bronce Final; Edad del Hierro; Portugal.

\begin{abstract}
In the past few years there has been a significant increase in the number of carnelian adornments documented in Late Bronze Age and Iron Age sites of southern Portugal, with more than fifty beads and pendants made from this material being currently known. We present a first synthesis regarding these pieces, which aims to discuss their typology, chronology and distribution, but also their possible origin, which is most likely to be found in the Eastern Mediterranean.
\end{abstract}

Key words. Carnelian; Adornment; Late Bronze Age; Iron Age; Portugal. 


\section{LA CORNALINA ANTIGUA: UNA BREVE IN- TRODUCCIÓN}

La cornalina -variante rojiza de la calcedonia, un tipo de cuarzo criptocristalino- ha sido utilizada para la producción de elementos de adorno desde fechas muy tempranas. De hecho, los abalorios de cornalina más antiguos del área mediterránea se han documentado en contextos del Neolítico Precerámico B (PPNB) del corredor siropalestino (Groman-Yaroslavski y BarYosef, 2015; Alarashi, 2016) y de Chipre (Rigaud, Serrand y Guilaine, 2017: fig. 7, k).

Sin embargo, su producción y difusión en estos momentos tan tempranos se habrán visto limitadas por la desigual distribución de esta piedra semipreciosa en la naturaleza (Fig. 1), ya que los principales depósitos de cornalina del Viejo Mundo se encuentran en la región de Gujarat, en el Noroeste de India (Roux, 2000). Por esa razón, el mayor desarrollo y difusión de los adornos realizados con este material en el Oriente Próximo no se produjo hasta el III milenio a.n.e., período en el que el establecimiento de estrechas relaciones comerciales con la floreciente civilización del Valle del Indo resultó en la llegada a Mesopotamia de abundantes elementos de collar de cornalina de producción india (Inizan, 1999; 2000).

De hecho, y a pesar de la presencia de depósitos menos expresivos de cornalina en otras áreas del Oriente Medio, como Afganistán, el Planalto Iraní, el Alto Eufrates o Armenia (Inizan, 1999: fig. 1; Brunet, 2009) (Fig. 1), tanto la tipología de las cuentas (Reade,
1979; Inizan, 1999; 2000) como los análisis que se han llevado a cabo de la técnica productiva (Matarasso y Roux, 1999; Roux, 2000) demuestran el origen surasiático de estas piezas.

Sin embargo, este predominio de los productos indios parece haber dado lugar, ya en el II milenio, a un panorama más diverso en el que la identificación del origen de los elementos en cornalina resulta progresivamente más compleja. De hecho, y aparte de los ya mencionados depósitos secundarios del Oriente Medio o del Cáucaso, cuya exploración podría remontar a estos momentos (Brunet, 2009), en este período parece también perfectamente documentada la exploración de las fuentes de cornalina presentes en Egipto.

Egipto, donde los adornos de cornalina están presentes al menos desde el Periodo Predinástico (Xia, 2014: 77 y ss.), puede haber sido, de hecho, el segundo gran foco de difusión de la cornalina en el mundo antiguo, gracias a las fuentes de este mineral presentes tanto en el Desierto Occidental como, sobre todo, en Núbia (Harrell y Storemyr, 2009: 51). La incorporación de este territorio en los dominios faraónicos durante el período de expansionismo militar de la XVIII Dinastía podría de hecho ayudar a explicar la creciente popularidad de la cornalina durante el Imperio Nuevo (Xia, 2014: 118).

Durante la segunda mitad del II milenio a.n.e. la cornalina sigue siendo frecuente también en el área siro-palestina y en Mesopotamia, como atestiguan los hallazgos de Ugarit (Caubet y Yon, 2006), Megiddo (Hall, 2016), Mari (Jean-Marie, 1999) o Assur

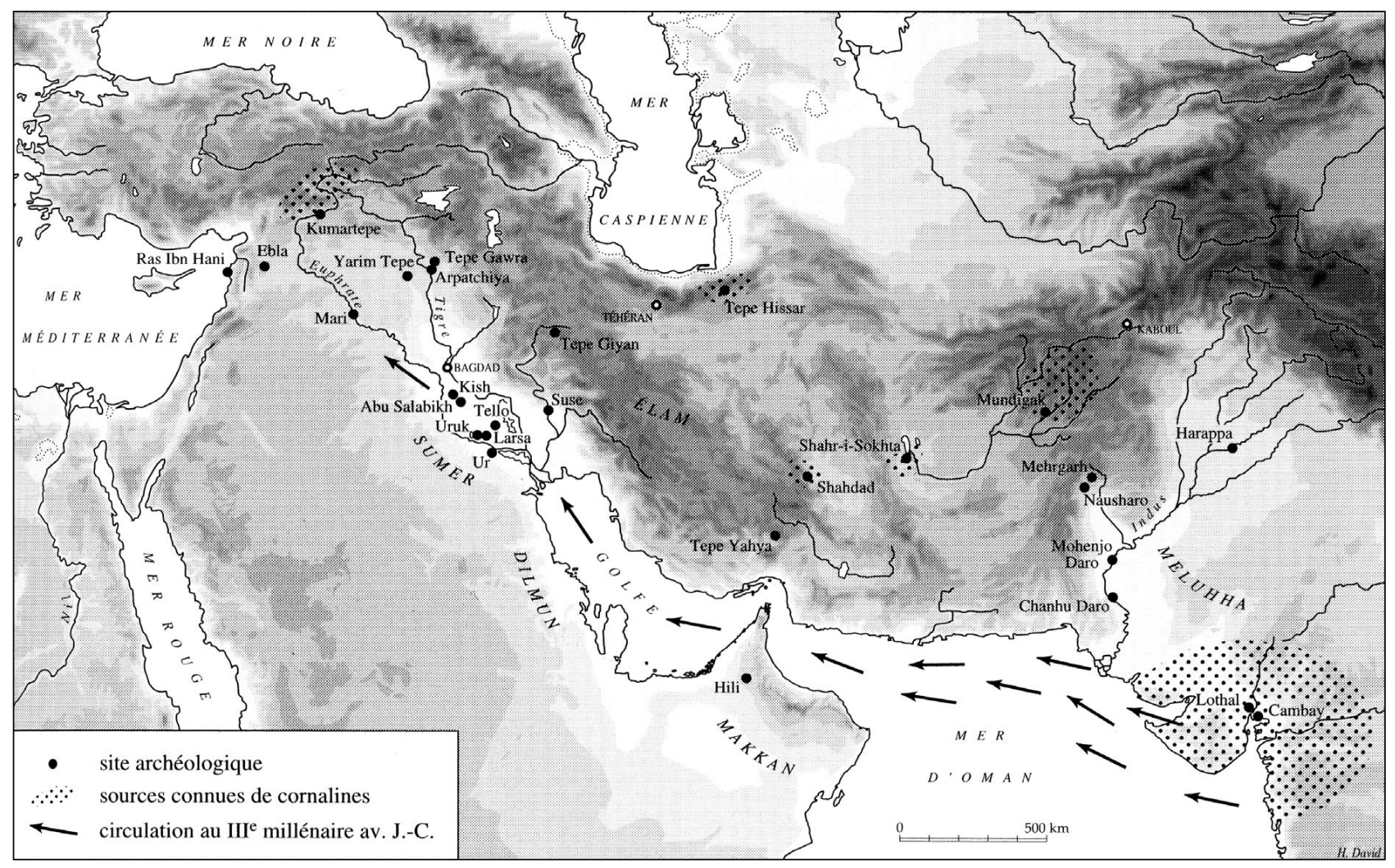

Figura 1: Principales fuentes de cornalina en el Oriente Próximo y Medio (en puntillado) (Inizan, 1999). 


\begin{tabular}{|c|c|c|c|c|c|}
\hline Yacimiento & Contexto & Cronologia & Tipología & Dimensiones & Bibliografía primária \\
\hline \multicolumn{6}{|c|}{ BRONCE FINAL } \\
\hline \multicolumn{6}{|c|}{ CUENTAS } \\
\hline Corôa do Frade & Superfície & s. VIII? & Bitroncocónica & $1,2 \mathrm{x} 0,74 \mathrm{~cm}$ & Arnaud, 1979 \\
\hline Corôa do Frade & Superfície & s. VIII? & Bitroncocónica & $1,1 \mathrm{x} 0,74 \mathrm{~cm}$ & Arnaud, 1979 \\
\hline Alto C. Serra & Superfície? & ND & Bitroncocónica & $1 \times 0,6 \mathrm{~cm}$ & Gibson et al., 1998 \\
\hline Martes & ND & ND & Bitroncocónica & ND & Calado, Barradas \& Mataloto, 1999 \\
\hline C. Ratinhos & $\mathrm{B} 1 / \mathrm{IIc}$ & ss. XIII-IX & Semi-esférica & $1,2 \times 1,3 \mathrm{~cm}$ & Berrocal-Rangel \& Silva, 2010 \\
\hline C. Ratinhos & $\mathrm{B} 1 / \mathrm{IIc}$ & ss. XIII-IX & Cilíndrica & $1,3 \times 0,9 \mathrm{~cm}$ & Berrocal-Rangel \& Silva, 2010 \\
\hline C. Ratinhos & D1/IIc & ss. XIII-IX & Esférica achat. & $1,95 \times 1,45 \mathrm{~cm}$ & Berrocal-Rangel \& Silva, 2010 \\
\hline C. Ratinhos & A1/IIa & f. s. IX - i. VIII & Bitroncocónica & $0,9 \times 0,5 \mathrm{~cm}$ & Berrocal-Rangel \& Silva, 2010 \\
\hline C. Ratinhos & A1/IIa & f. s. IX - i. VIII & Esférica achat. & $1,4 \times 1,2 \mathrm{~cm}$ & Berrocal-Rangel \& Silva, 2010 \\
\hline C. Ratinhos & B1/IIa & f. s. IX - i. VIII & Discoide & $1,05 \mathrm{x} 0,6 \mathrm{~cm}$ & Berrocal-Rangel \& Silva, 2010 \\
\hline C. Ratinhos & $\mathrm{C} 1 / \mathrm{IIa}$ & f. s. IX - i. VIII & Bitroncocónica & $1,55 \mathrm{x} 0,9 \mathrm{~cm}$ & Berrocal-Rangel \& Silva, 2010 \\
\hline C. Ratinhos & $\mathrm{D} 2 / \mathrm{IIa}$ & f. s. IX - i. VIII & Bitroncocónica & $1,5 \times 1,05 \mathrm{~cm}$ & Berrocal-Rangel \& Silva, 2010 \\
\hline C. Ratinhos & $\mathrm{C} 1 / \mathrm{Ib}$ & s. VIII & Cilíndrica & $1,2 \times 1,1 \mathrm{~cm}$ & Berrocal-Rangel \& Silva, 2010 \\
\hline C. Ratinhos & $\mathrm{C} 1 / \mathrm{Ib}$ & s. VIII & Bitroncocónica & $1,4 \times 0,8 \mathrm{~cm}$ & Berrocal-Rangel \& Silva, 2010 \\
\hline C. Ratinhos & $\mathrm{C} 2 / \mathrm{Ib}$ & s. VIII & Bitroncocónica & $0,75 \times 0,75 \mathrm{~cm}$ & Berrocal-Rangel \& Silva, 2010 \\
\hline C. Ratinhos & $\mathrm{A} 2 / \mathrm{Ib}$ & s. VIII & Bitroncocónica & $1,1 \times 0,6 \mathrm{~cm}$ & Berrocal-Rangel \& Silva, 2010 \\
\hline C. Ratinhos & $\mathrm{D} 1 / \mathrm{Ic}$ & s. VIII? & Bitroncocónica & ND & Berrocal-Rangel \& Silva, 2010 \\
\hline Álamo & Superfície & ND & Bitroncocónica & $1,6 \mathrm{x} 0,9 \mathrm{~cm}$ & Soares, 2005 \\
\hline Álamo & Superfície & ND & Bitroncocónica & $1,5 \times 0,9 \mathrm{~cm}$ & Soares, 2005 \\
\hline Álamo & Superfície & ND & Bitroncocónica & $1,2 \times 0,6 \mathrm{~cm}$ & Soares, 2005 \\
\hline Salsa 3 & ND & ND & Bitroncocónica & ND & Gonçalves et al., 2011 \\
\hline Lousal & ND & ND & Elipsoide & ND & Cardoso, 2006 \\
\hline \multicolumn{6}{|c|}{ COLGANTES } \\
\hline M.te Outeiro & ND & ND & Fitomorfo & $1,6 \times 0,9 \mathrm{~cm}$ & Mataloto, 2012 \\
\hline C. Ratinhos & $\mathrm{D} 1 / \mathrm{Ib}$ & s. VIII & Lágrima & $1,75 \mathrm{x} 1,2 \mathrm{~cm}$ & Berrocal-Rangel \& Silva, 2010 \\
\hline Salsa 3 & ND & ND & Fitomorfo & ND & Gonçalves et al., 2011 \\
\hline \multicolumn{6}{|c|}{ EDAD DEL HIERRO } \\
\hline O. Sr. Mártires & ND & ND & Esférica & $1,1 \mathrm{x} 1,1 \mathrm{~cm}$ & Gomes, 2016 \\
\hline Vinha Caliças 4 & & 2. ${ }^{\mathrm{a}} \mathrm{m} . \mathrm{s} . \mathrm{VI}$ & Bitroncocónica & $1,2 \times 0,9 \mathrm{~cm}$ & Arruda et al., 2017 \\
\hline Vinha Caliças 4 & & 2. ${ }^{\mathrm{a}} \mathrm{m} . \mathrm{s} . \mathrm{VI}$ & Bitroncocónica & $0,75 \times 0,55 \mathrm{~cm}$ & Arruda et al., 2017 \\
\hline Qta. Estácio 6 & & s. VI & Bitroncocónica & $1 \times 0,6 \mathrm{~cm}$ & Pereiro, Mataloto \& Borges, 2017 \\
\hline Herd. Gaio & Tumba $1 ?$ & f. s. VI - s. V & Bitroncocónica & $0,7 \times 0,5 \mathrm{~cm}$ & Costa, 1972 \\
\hline Herd. Gaio & Tumba $1 ?$ & f. s. VI - s. V & Bitroncocónica & $0,8 \times 0,75 \mathrm{~cm}$ & Costa, 1972 \\
\hline Herd. Gaio & Tumba $1 ?$ & f. s. VI - s. V & Bitroncocónica & $0,8 \times 0,5 \mathrm{~cm}$ & Costa, 1972 \\
\hline Herd. Gaio & Tumba $1 ?$ & f. s. VI - s. V & Bitroncocónica & $0,9 \mathrm{x} 0,4 \mathrm{~cm}$ & Costa, 1972 \\
\hline Herd. Gaio & Tumba $1 ?$ & f. s. VI - s. V & Bitroncocónica & $0,85 \mathrm{x} 0,4 \mathrm{~cm}$ & Costa, 1972 \\
\hline Herd. Gaio & Tumba $1 ?$ & f. s. VI - s. V & Cilíndrica & $0,7 \times 0,9 \mathrm{~cm}$ & Costa, 1972 \\
\hline Fonte Santa & Tumba 4 & s. VI-V & Cilíndrica? & ND & Beirão, 1986 \\
\hline Fonte Santa & Tumba 4 & s. VI-V & ND & ND & Beirão, 1986 \\
\hline Mealha Nova & Superfície & s. VI-V? & ND & ND & Dias, Beirão \& Coelho, 1970 \\
\hline Garvão & Q.1.19/C3b & f. s. III - i. s. II & Esférica achat. & $0,5 \times 0,3 \mathrm{~cm}$ & Beirão et al., 1985 \\
\hline Garvão & Q.1.19/C3b & f. s. III - i. s. II & Esférica achat. & $0,5 \times 0,3 \mathrm{~cm}$ & Beirão et al., 1985 \\
\hline Garvão & Q.1.19/C3b & f. s. III -i. s. II & Esférica achat. & $0,5 \mathrm{x} 0,3 \mathrm{~cm}$ & Beirão et al., 1985 \\
\hline Garvão & Q.1.19/C3b & f. s. III - i. s. II & Cilíndrica & $0,4 \times 0,5 \mathrm{~cm}$ & Beirão et al., 1985 \\
\hline
\end{tabular}




\begin{tabular}{|c|c|c|c|c|c|}
\hline Garvão & Q.1.13/C3c & f. s. III - i. s. II & Discoide & $1,1 \times 0,5 \mathrm{~cm}$ & Beirão et al., 1985 \\
\hline Garvão & Vala & f. s. III -i. s. II & Discoide & $0,8 \mathrm{x} 0,3 \mathrm{~cm}$ & Beirão et al., 1985 \\
\hline Garvão & $\mathrm{Q} 2 / \mathrm{C} 4$ & f. s. III - i. s. II & Bitroncocónica & $1,6 \times 1 \mathrm{~cm}$ & Beirão et al., 1985 \\
\hline Garvão & $\mathrm{Q} 2 / \mathrm{C} 4$ & f. s. III - i. s. II & Discoide & $0,9 \mathrm{x} 0,5 \mathrm{~cm}$ & Beirão et al., 1985 \\
\hline \multicolumn{6}{|c|}{ COLGANTES } \\
\hline Vinha Caliças 4 & Tumba 48 & 2. ${ }^{\mathrm{a}} \mathrm{m} . \mathrm{s} . \mathrm{VI}$ & Fitomorfo & $1,6 \times 0,75 \mathrm{~cm}$ & Arruda et al., 2017 \\
\hline M.te Bolor 1-2 & & s. VI & Fitomorfo & $2,5 \mathrm{x} 1,2 \mathrm{~cm}$ & Soares et al., 2017 \\
\hline Cabeço Vaca & Tumba 1 & 2. ${ }^{\mathrm{a}} \mathrm{m} . \mathrm{s} . \mathrm{VI}$ & Fitomorfo & $1,1 \times 0,7 \mathrm{~cm}$ & Cardoso \& Gradim, 2006 \\
\hline Pardieiro & Tumba & s. VI-V & Amigdaloide & $3,8 \mathrm{x} 1,95 \mathrm{~cm}$ & Beirão, 1990 \\
\hline
\end{tabular}

Figura 2: Características generales de los elementos de cornalina del sur de Portugal.

(Wartke, 1999). Por otra parte, en este período los abalorios de cornalina se difunden hacia el Mediterráneo Oriental y el Egeo, como se ha documentado en Chipre (Courtois, 1984), en Creta (Phillips, 2008) y en Grecia Continental (Adler, 1996: 45; Martín de la Cruz, 2004), hasta alcanzar incluso el Mediterráneo Central (Vagnetti, 1982: 170-171). Su incorporación en las rutas comerciales de estos momentos se encuentra además bien documentada por la presencia de elementos de este tipo en el pecio de Ulu Burun (Ingram, 2005: 3).

En un contexto de amplia difusión como este, el origen de la materia prima y de los propios modelos de los abalorios se convierte en este período en una cuestión de difícil resolución ya que, a pesar de las propuestas de algunos autores (Caubet y Yon, 2006), no parece totalmente claro que la cornalina que circula en esta etapa sea todavía exclusiva o predominantemente originaria de India, sobre todo si, como quedó dicho, Egipto - que ejerció en esta fase una considerable influencia cultural en todo el Mediterráneo Oriental (Mieroop, 2007)- disponía también de fuentes de este mineral cuya explotación está bien documentada (Harrell y Storemyr, 2009: 51).

De todos modos, y tras el final del Imperio Nuevo, la cornalina parece haber perdido popularidad en Egipto, lo cual quizás explique su presencia aparentemente menor también en el ámbito del Oriente Próximo, aunque esto también puede responder a una menor atención investigadora. Lo que sí parece claro es que, a pesar de ser peor conocida, la cornalina seguirá formando parte de los inventarios de las materias primas de los abalorios en esta región durante la Edad del Hierro (Hall, 2016).

En lo tocante al Mediterráneo Occidental, la cornalina parece estar totalmente ausente de los inventarios arqueológicos hasta el Bronce Final. Esa ausencia no es sorprendente si se considera que hasta el momento no se han documentado fuentes de esta materia prima en la Península Ibérica (Martín de la Cruz, 2004; Martín de la Cruz et al., 2005), lo cual, sumado al particular contexto histórico de apertura al Mediterráneo en que se documentan las primeras presencias de elementos de cornalina, lleva a pensar que los mismos correspondan muy probablemente a importaciones (Martín de la Cruz, 2004; 2008; Martín de la Cruz et al., 2005; Torres Ortiz, 2008: 77-78), hipótesis que la propia tipología de algunas piezas parece avalar.

El actual territorio portugués, a pesar de su evidente situación geográfica periférica con respecto al ámbito mediterráneo, también ha conocido en estos mismos momentos una relativa apertura a los influjos procedentes de dicho ámbito, ya sea por vía directa o a través de la mediación de otras regiones peninsulares (Arruda, 2008; Vilaça, 2008).

En ese marco, se produjo igualmente la llegada de los primeros elementos de cornalina al Far West atlántico (véase infra). Dichos elementos, aunque relativamente raros, se encuentran bien documentados en contextos del Bronce Final regional, y siguen presentes ya en la Edad del Hierro.

Sin embargo, estos abalorios, cuyo número ha aumentado de forma significativa en los últimos años hasta sobrepasar las cinco decenas -se conoce actualmente un mínimo de 52 ejemplares en total (Fig. 2)-, no han sido todavía objeto de un análisis de conjunto que permita valorar su distribución geográfica y cronológica y su tipología.

Hay que señalar que la valoración global de este conjunto se enfrenta a ciertas dificultades. Desde luego, la propia identificación de la materia prima no resulta fácil en un simple análisis macroscópico, ya que la cornalina puede en algunos casos llegar a confundirse con otras variantes del cuarzo.

Esa dificultad puede obviarse mediante análisis en laboratorio, como se verificó en el caso modélico de Castro dos Ratinhos (Gonçalves y Soares, 2010), pero lamentablemente el corpus de dichos análisis sigue siendo escueto en el sur de Portugal (Gonçalves y Soares, 2010; Gonçalves et al., 2011), así como en todo el territorio peninsular (Martín de la Cruz, 2004; Martín de la Cruz et al., 2005).

No es por eso imposible que algunos elementos de cornalina sigan sin identificarse como tal, ni que algunas de las piezas que abajo se estudian puedan, en futuras lecturas, considerarse como pertenecientes a otras categorías mineralógicas. Sin embargo, y aun teniendo todas estas limitaciones en mente, los 
datos ya disponibles sí parecen lo suficientemente expresivos como para justificar un primer análisis de conjunto, que se tratará de desarrollar en las páginas que siguen.

\section{LA CORNALINA EN EL BRONCE FINAL}

Los más antiguos elementos de cornalina hasta el momento documentados en el sur del territorio portugués provienen de contextos genéricamente pertenecientes al Bronce Final regional (ss. XIII-IX/VIII a.n.e.) (Fig. 3). Sin embargo, la tarea de fechar con exactitud el momento de llegada de estos abalorios dentro de dicha etapa histórica resulta muy compleja, debido sobre todo a la escasa definición cronológica de sus contextos de hallazgo.

El único yacimiento que podría contribuir para aclarar la fecha de llegada de los primeros elementos producidos con esta materia prima es el Castro dos Ratinhos (Moura) (Berrocal-Rangel y Silva, 2010), ya que las cuentas y colgantes allí exhumados, además de muy abundantes, disponen de contextos estratigráficos bien documentados y publicados.

Sin embargo, los más antiguos elementos en cornalina de este yacimiento se han documentado en contextos pertenecientes a su Fase 2a (Berrocal-Rangel y Silva, 2010: 228 y fig. 112), para la cual de momento se ha obtenido una sola fecha radiométrica, que ha proporcionado un intervalo muy amplio, entre el siglo XIII y el IX a.n.e. (Soares y Martins, 2010: tabs. 24-25), lo cual no permite acotar la cronología de llegada de esas piezas más precoces.

De todos modos, lo que sí parece claro es que dichas piezas serían anteriores a los primeros contactos de este yacimiento con el mundo colonial fenicio, a los cuales sin embargo sí se podría hipotéticamente achacar la responsabilidad por la introducción de los elementos presentes ya en horizontes de las Fases 1b y 1a del yacimiento (Berrocal-Rangel y Silva, 2010: 150, 156 y 186 y figs. 65, 68 y 87), fechadas entre finales del siglo IX y mediados del VIII a.n.e. (Soares y Martins, 2010: tabs. 24-25).

Las piezas de Corôa do Frade (Arnaud, 1979: fig. 8, nn. 3, 6-7) podrían igualmente integrarse en un horizonte tardío, ya que en este yacimiento se ha recuperado también una fíbula de dupla mola (Arnaud, 1979: fig. 6, n.7), lo cual indica que el poblado subsistió hasta los momentos terminales del Bronce Final regional, posiblemente entre el siglo VIII y el VII a.n.e. (Arnaud, 1979: 90). Sin embargo, al tratarse de materiales recogidos en superficie la asociación de las cuentas de cornalina de este yacimiento con su fase más tardía no puede considerarse totalmente demostrada.

Queda así por aclarar si los adornos en cornalina están presentes ya desde los momentos más antiguos del Bronce Final o si su introducción se produce en momentos avanzados de esta etapa histórica, cuestión relevante ya que, como bien señaló M. Torres Ortiz

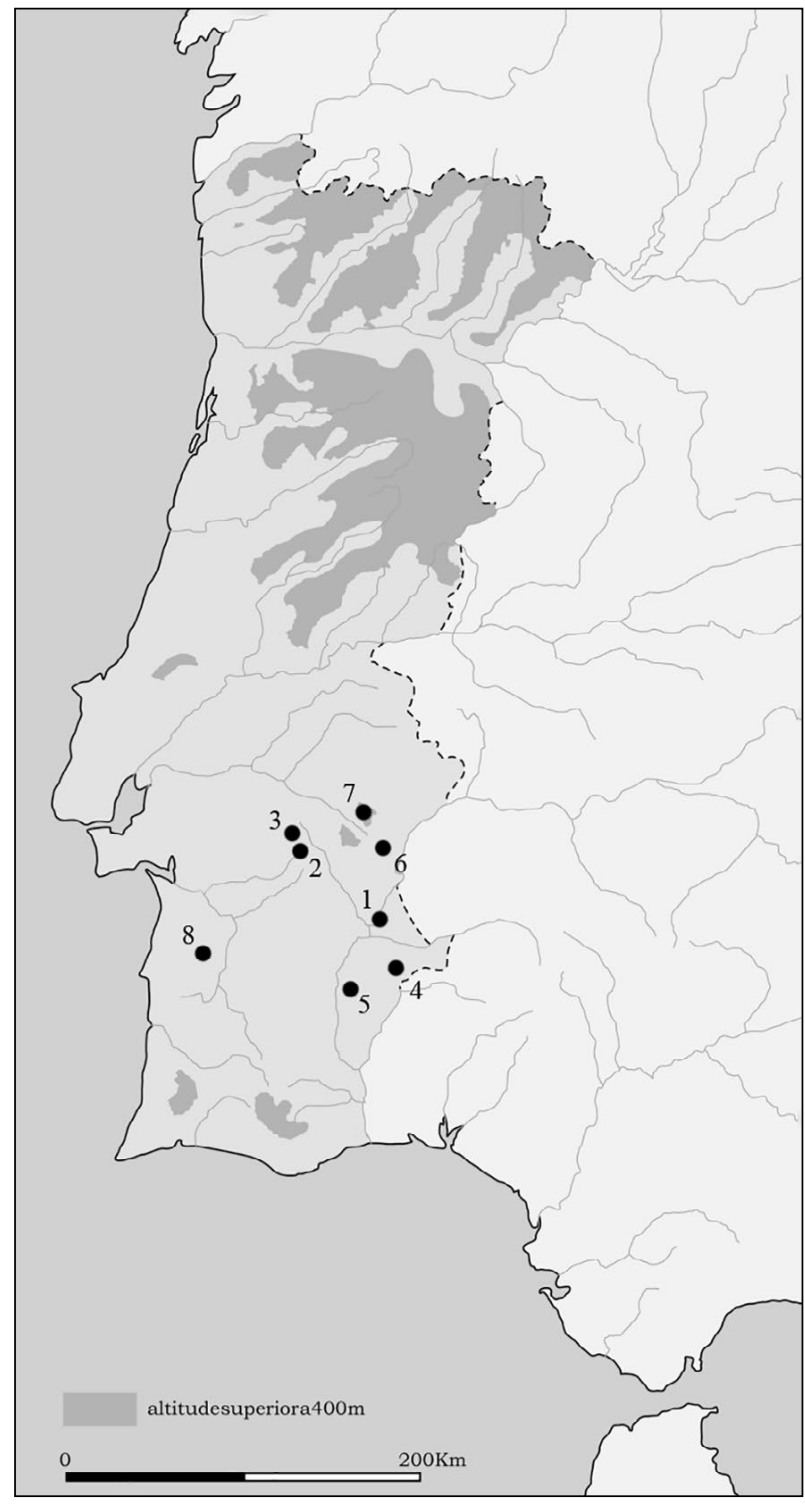

Figura 3: Distribución de los elementos de cornalina del Bronce Final en el sur de Portugal: 1 - Castro dos Ratinhos (Moura); 2 Corôa do Frade (Évora); 3 -Alto do Castelinho da Serra (Évora); 4 - Salsa 3 (Serpa); 5 - Álamo (Serpa); 6 - Monte do Outeiro 2 (Reguengos de Monsaraz); 7 - Martes (Redondo); 8 - Lousal (Grândola). Ubicaciones aproximadas.

(2008: 77-78), ello tiene necesariamente un significado central a la hora de valorar las vías y los agentes de la introducción de estos elementos en la Península Ibérica.

Ahora bien, desde el punto de vista tipológico las piezas en cornalina documentadas en contextos del Bronce Final del sur de Portugal corresponden a elementos de collar de dos tipos: cuentas y colgantes. Las primeras pueden dividirse en cuatro grandes grupos tipológicos: cuentas bitroncocónicas, cuentas cilíndricas, cuentas esféricas/semiesféricas y cuentas discoides.

Las cuentas de morfología bitroncocónica son las más frecuentes en el conjunto, sumando un total de al menos 15 ejemplares. 
En Castro dos Ratinhos, Moura, este es el tipo más común, con seis o siete ejemplares documentados ${ }^{1}$ (Berrocal-Rangel y Silva, 2010: 150, 156 y 186 y figs. 65, 68 y 87; Gonçales y Soares, 2010; Gonçalves et al., 2011) (Fig. 4, nn. 7-12), todos pertenecientes a las fases más tardías del yacimiento (1b y 1a), lo cual podría estar indicando que las cuentas de esta morfología se introducen a finales de la Edad del Bronce, ya en el marco del comercio fenicio en el Extremo Occidente (Berrocal-Rangel y Silva, 2010: 316).

Las cuentas bitroncocónicas están además representadas en los yacimientos de Corôa do Frade, Évora (dos ejemplares - Arnaud, 1979: fig. 8, nn. 3, 6-7) (Fig. 4, nn. 13-14), de Martes, Redondo (más de un ejemplar, número no específicado - Calado, Barradas y Mataloto, 1999: 7), de Salsa 3, Serpa (un ejemplar - Gonçalves et al., 2011) y de Álamo, también en Serpa (tres ejemplares - Soares, 2005: fig. 13, nn.6-8; Gonçalves, 2005; Gonçalves et al., 2011) (Fig. 4, nn. 15-17).

Otro ejemplar, recogido en Alto do Castelinho da Serra, Évora, podría también pertenecer al Bronce Final (Gibson et al., 1998: fig. 15, n.2) (Fig. 4, n. 18). Sin embargo, al tratarse de una pieza al parecer sin contexto, su marco cronológico no está totalmente claro, sobre todo porque también se ha documentado una ocupación de la Edad del Hierro en el yacimiento (Gibson et al., 1998).

Fuera del territorio en estudio estas piezas cuentan con un buen paralelo ya al norte del Tajo en el poblado de Alto das Cabeças, Oeiras, donde se ha recogido una cuenta de esta tipología también en un ambiente del Bronce Final (Cardoso y Cardoso, 1996: fig. 5, n.5). Otra pieza de morfología idéntica se ha recuperado en el poblado de Monte da Pena, en Torres Vedras, aunque en este caso la materia prima se haya identificado como ágata (Madeira et al., 1972: 211 y fig. 3).

Cabría, por otra parte, recordar en este contexto que las cuentas bitroncocónicas, frecuentes en el Oriente Próximo (Daviau y Steiner, 2017: 227-230) e igualmente presentes en el ámbito micénico (Wilkie, 2000-2001: 12), suelen predominar en los inventarios de los abalorios de cornalina de las etapas avanzadas de la Edad del Bronce peninsular.

Así lo demuestra, por ejemplo, una reciente revisión de los contextos funerarios del Bronce Final del Sureste de la Península, donde los únicos elementos en cornalina documentados, fechados entre mediados

\footnotetext{
1. Existe una pequeña discrepancia con respecto a la cuantificación de las cuentas de cornalina de Castro dos Ratinhos, ya que en el inventario general de los materiales del yacimiento (Berrocal-Rangel y Silva, 2010) consta al menos una cuenta bitroncocónica (CRAT04/D2/IIa/L001) no referida en el estudio analítico dedicado a estos materiales (Gonçalves y Silva, 2010); por otra parte, en dicho estudio analítico -donde se indica que todas las cuentas líticas han sido analizadas- se cita una cuenta (CRAT05/D1/Ic/L002) de este mismo tipo no recogida en el inventario global de materiales.
}

del siglo IX y mediados-finales del VIII a.n.e., pertenecen exclusivamente a esta tipología (Lorrio, 2008: 290-291). A este mismo horizonte cronológico pueden atribuirse además tanto una cuenta bitroncocónica de Peña Negra (Martínez Mira y Vilaplana Ortego, 2014: 863) así como otro ejemplar recogido en la cabaña de Pocito Chico (Ruiz Gil y López Amador, 2004).

Aunque menos comunes, los ejemplares de morfología cilíndrica están también relativamente bien representados, aunque solo se hayan documentado piezas de este tipo en Castro dos Ratinhos. En este yacimiento se han recogido dos de estas piezas, una de las cuales proviene de los horizontes estratigráficos más antiguos del yacimiento (Fase 2 - Berrocal-Rangel y Silva, 2010: 228 y fig. 112) mientras la otra se puede asociar a momentos avanzados de su diacronía (Fase 1a-Berrocal-Rangel y Silva, 2010: 150 y fig. 65) (Fig. 4, nn. 4-5).

Las cuentas esféricas o semiesféricas son también relativamente raras. Las primeras están representadas por dos ejemplares esféricos achatados, igualmente de Castro dos Ratinhos (Fases $1 \mathrm{~b}$ y 2 - Berrocal-Rangel y Silva, 2010: 186, 228 y figs. 87 y 112) (Fig. 4, nn. 2-3), mientras la tipología semiesférica se encuentra representada por una única pieza de este mismo yacimiento (Fase 2a - Berrocal-Rangel y Silva, 2010: 228 y fig. 112) (Fig. 4, n.1).

El último grupo tipológico, el de las cuentas discoides, se encuentra igualmente representado por un único ejemplar, proveniente una vez más de Castro dos Ratinhos (Fase 1b-Berrocal-Rangel y Silva, 2010: 186 y fig. 87) (Fig. 4, n. 6).

Sin embargo, y al margen de estos cuatro grupos más bien definidos, cabría señalar la presencia en el monumento megalítico de Lousal, en Grândola, reutilizado al parecer durante el Bronce Final, de una cuenta todavía mal caracterizada pero descrita como de morfología elipsoide (Cardoso, 2004: 195). Por ende, y si no se tratara en realidad de una pieza cilíndrica o cilíndrica abombada, esta cuenta constituiría en sí misma un quinto grupo tipológico.

Cabría señalar que, tal y como ocurre con las piezas bitroncocónicas, prácticamente todos estos tipos minoritarios tienen paralelos en el Mediterráneo Oriental (Phillips, 2008: 248; Daviau y Steiner, 2017: 224 y ss.) y en el Egeo (Wilkie, 2000-2001: 12). Las cuentas cilíndricas y esféricas cuentan además con paralelos en el yacimiento de Peña Negra (Martínez Mira y Vilaplana Ortego, 2014: 864-865).

Las cuentas de tipología esférica o esférica achatada tienen también paralelos en contextos del Bronce Final del Centro de Portugal, en particular de los poblados de Alegrios, Idanha-a-Nova (Vilaça, 1995: 179 y Est. CXLIV, n.11) y posiblemente de Cabeço de Alcaínça, Mafra (Ponce, 2012: 65-66), aunque este último corresponda a un hallazgo de superficie.

En cuanto a los colgantes, el conjunto actualmente conocido puede, a pesar de su reducida dimensión (tres ejemplares), dividirse en dos grupos tipológicos. El más 

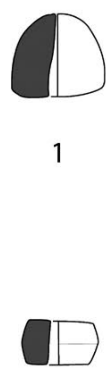

6

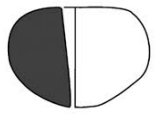

2

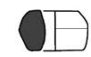

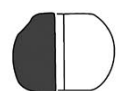

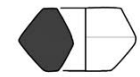

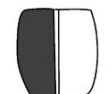

4

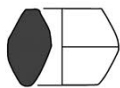

9

12

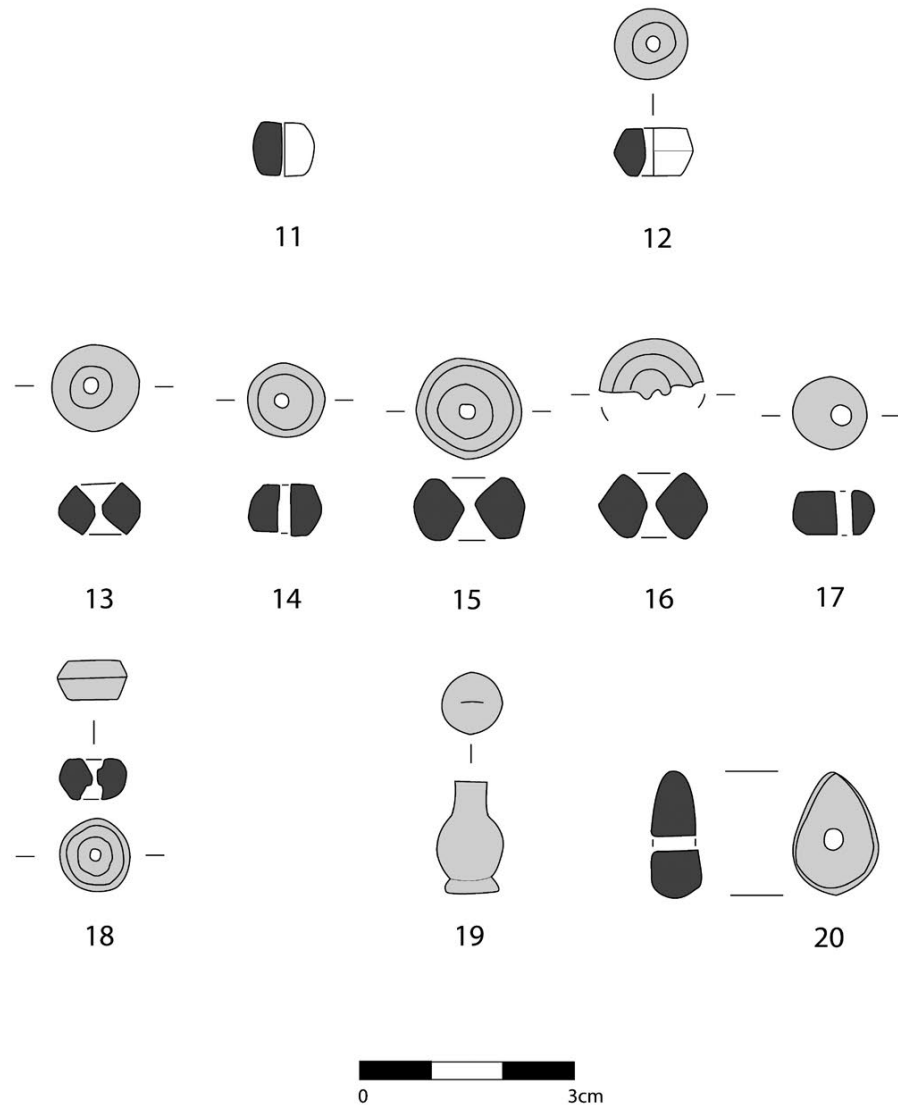

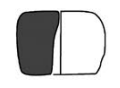

5

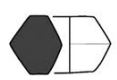

10

Figura 4: Elementos de cornalina del Bronce Final: 1-12 - Castro dos Ratinhos (Berrocal Rangel y Silva, 2010); 13-14 - Corôa do Frade (Arnaud, 1979); 15-17 - Álamo (Soares, 2005, adaptado); 18 - Alto do Castelinho da Serra (Gibson et al., 1998); 19 - Monte do Outeiro 2 (Mataloto 2012, adaptado); 20 - Castro dos Ratinhos (Berrocal-Rangel y Silva, 2010, adaptado).

característico de ellos es sin duda el de los colgantes fitomorfos, representado por dos ejemplares. Estas piezas corresponden a pequeños colgantes de morfología compuesta, con una base de sección trapezoidal y un cuerpo globular coronado por un apéndice alargado en el cual se abre lateralmente una perforación para suspensión. Estos colgantes se pueden integrar en el Tipo B.3.d de la clasificación universal de H. C. Beck (1928: 28).

En el sur de Portugal, se han documentado colgantes de este tipo en contextos del Bronce Final en Monte do Outeiro 2 (Redondo) (Mataloto, 2012: fig. 23) (Fig. 4, n. 19) y en Salsa 3 (Serpa) (Gonçalves et al., 2011: fig.
1). Estos ejemplares portugueses deben sin embargo relacionarse con el más amplio conjunto de colgantes de esta misma tipología documentado en la Baja Andalucía en contextos del Bronce Final o de transición hacia la Edad del Hierro.

De hecho, en esa región los colgantes del tipo en cuestión son algo más frecuentes, con ejemplares documentados tanto en la provincia de Cádiz - en la Sierra de San Cristóbal (Ruiz Mata, Pérez Pérez y Martín de la Cruz, 2004), en Pocito Chico (Ruiz Gil y López Amador, 2004) y en las Mesas de Asta (Martín de la Cruz, 2004: 17) - como en la de Córdoba -en los Castillejos de la Granjuela (Vera Rodríguez, 2004; Martín de la Cruz et 
al., 2005) y en el Cabezo de Córdoba (Sánchez Romero y Martín de la Cruz, 2004).

Como se ha señalado en repetidas ocasiones (Martín de la Cruz, 2004; Martín de la Cruz et al., 2005), estos colgantes tienen sus mejores paralelos en el Mediterráneo Oriental, y muy especialmente en Egipto (Müller-Winckler, 1987: 277-280). De hecho, y a pesar de lecturas alternativas que proponen un origen indio para estos abalorios (Caubet y Yon, 2006), la hipótesis de que este modelo de colgante tenga origen en el País del Nilo disfruta hoy de una amplia aceptación (Phillips, 2008: 140-145).

De hecho, colgantes de este tipo se documentan en Egipto desde inicios de la Dinastía XVIII; su fase de mayor popularidad coincide en efecto con el período de Amarna, aunque se prolongue en el tiempo a lo largo de la Dinastía XIX (Phillips, 2008: 141). Aparte de la cornalina, cuentas de este mismo tipo se han producido en distintas materias primas, en particular la fayenza (Phillips, 2008: 141).

Estos elementos se han difundido muy probablemente a partir de Egipto por el Mediterráneo Oriental, como quedó documentado en el corredor siro-palestino (McGovern, 1985: 47-49), en Chipre (Buchholz y Karagheorgis, 1973: 166 y 487), en Creta (Phillips, 2008: 140-145) y en Grecia Continental, donde se han recogido sendos ejemplares en las necrópolis micénicas de Perati (Iakovides, 1969) y Coo (Morricone, 19651966). Estos colgantes se han documentado también en el Mediterráneo Central, en la isla eólica de Lipari (Bernabò Brea y Cavalier, 1960: 115; Vagnetti, 1982: 170-171).

Los colgantes de este grupo se pueden dividir en dos variantes: una en que las piezas poseen un dorso plano, representada en Portugal por la pieza de Monte do Outeiro 2 (Mataloto, 2012: fig. 23); y otra compuesta por piezas de bulto redondo, a la que al parecer pertenece el ejemplar de Salsa 3 (Gonçalves et al., 2011: fig. 1).

Por otra parte, y desde un punto de vista estilístico, las piezas orientales han sido igualmente divididas por C. Müller-Wincler (1987: 279-280) en dos variantes: las que representan un elemento vegetal realista (Naturgetreue Variante) y las que lo representan de forma estilizada (Stilisierte Variante); todos los ejemplares portugueses $-y$ peninsulares- pertenecen claramente a esta última variante.

En cuanto a la identificación de dicho elemento se aprecia cierta confusión, que además se ha visto reflejada en la investigación peninsular. De hecho, estos colgantes son alternativamente descritos como representaciones de botellas (Bernabò y Cavalieri, 1960: 115; Karagheorgis, 1974: 72; Escacena Carrasco, 2008) -identificación que a pesar de visualmente pertinente parece poco adecuada desde un punto de vista iconográfico- o de algún tipo de elemento vegetal.

Esta última hipótesis es la que ha alcanzado mayor consenso, aunque la identidad del elemento vegetal concreto siga siendo controvertida. De hecho, y aparte de la identificación de dicho elemento como una cariópside de loto (Petrie, 1906: 45) -que aunque ocasionalmente mencionada en la bibliografía peninsular (Martín de la Cruz, 2004: 16; Torres Ortiz, 2008: 77) ha sido prácticamente descartada desde la refutación de R. Merrillees (1962: 291)- las opiniones se dividen entre la interpretación de estos colgantes como representaciones de adormideras (Papaver somniferus) (Merrillees, 1962: 291-292; Martín de la Cruz, 2004: 16; Torres Ortiz, 2008: 77), amapolas (Papaver rhoeas L.) (Phillips, 2008: 145) o de una planta de la familia del aciano, designada en inglés como cornflower (Centaurea depressa) (Müller-Winckler, 1987: 277; Hepper, 1990: 14; Phillips, 2008: 140-145).

Esta última hipótesis es hoy por hoy la que más apoyos recoge, al menos en el ámbito de la Egiptología, debido sobre todo a las evidencias arqueobotánicas del uso ornamental y de adorno de la Centaurea depressa en Egipto durante el Imperio Nuevo tras su introducción, probablemente desde el corredor siro-palestino, a inicios de la Dinastía XVIII (Hepper, 1990: 14).

Sin embargo, como bien señaló J. Phillips (2008: 145), es posible que la misma forma de colgante se haya utilizado para representar más de una planta, y que la llave para la identificación de la especie vegetal se encuentre en el color de la materia prima utilizada. Así, los colgantes de fayenza podrían representar flores de Centaurea depressa, con las que comparten la tonalidad azul, mientras los de cornalina, por su color rojizo, podrían representar amapolas, igualmente bien documentadas como plantas ornamentales en el mismo período (Phillips, 2008: 145).

Finalmente, y en cuanto a la cuestión de su cronología, los paralelos mediterráneos de las piezas en estudio no permiten aclarar los parámetros cronológicos de los ejemplares portugueses, y peninsulares en general, ya que estos colgantes parecen estar presentes desde mediados del siglo XV a.n.e. -caso de los ejemplares egipcios de inicios de la XVIII Dinastía- hasta al menos los siglos XI-IX a.n.e., en los cuales se puede fechar el ambiente cultural de las piezas halladas en Lipari (Torres Ortiz, 2008: 78).

Por otra parte, y considerando lo poco que se conoce hasta el momento sobre los contextos de las dos piezas portuguesas, no puede descartarse que las mismas pertenezcan a horizontes cronológicos más tardíos que sus congéneres mediterráneas antes comentadas.

Así, y como se ha propuesto para buena parte de los ejemplares andaluces (Torres Ortiz, 2008: 77-78), su introducción podría resultar ya de los primeros contactos con los colonos y comerciantes fenicios instalados en el litoral. Por otra parte, y como se verá adelante, tampoco faltan ejemplos más tardíos, tanto en Oriente como en Occidente, que atestiguan la larga duración de estos abalorios.

Aparte de estas dos piezas fitomorfas, el otro único colgante documentado en contextos del Bronce Final del sur de Portugal presenta una morfología sui generis, correspondiente a una pieza plana en forma de lágrima. 
Esta pieza se ha recuperado en Castro dos Ratinhos, en un contexto perteneciente a la fase 1a de este yacimiento (Berrocal-Rangel y Silva, 2010: 156 y fig. 68) (Fig. 4, n. 20), fechable por ende entre el segundo cuarto y finales del siglo VIII a.n.e. (Soares y Martins, 2010: 413). No se ha podido documentar ningún paralelo exacto para esta pieza.

\section{LA CORNALINA EN LA EDAD DEL HIERRO}

Durante la Edad del Hierro la cornalina seguirá presente en los inventarios de los objetos de adorno de las comunidades del sur de Portugal (Fig. 5). De hecho, esta materia prima es incluso algo más frecuente durante este período, con un total de 27 piezas documentadas, frente a las 25 presentes en contextos del Bronce Final.

Este hecho no resulta demasiado sorprendente, ya que la cornalina sigue siendo una presencia relativamente constante en la Edad del Hierro mediterránea, sobre todo en ambientes fenicios y púnicos. De hecho, se han identificado abalorios realizados con esta piedra semipreciosa en contextos tan expresivos como las necrópolis de Achziv (Mazar, 2004: 92-93), de Cartago (Quillard, 1979), de Cerdeña (Harden, 1962: fig. 103) o de Ibiza (Vives y Escudero, 1917: 77, apud AlmagroGorbea et al., 2004: 167; Fernández y Padró, 1982), así como entre los materiales del pecio de El Sec, en Mallorca (Arribas et al., 1987: 593).

En la Península Ibérica, los elementos de cornalina están bien documentados en múltiples contextos funerarios fenicios y púnicos, tal y como las sepulturas del Grupo C de la necrópolis de Villaricos, Almería (Astruc, 1951: 34), la Tumba 32 de Puente de Noy, Granada (Molina Fajardo, Ruiz Fernández y Huertas Jiménez, 1982: 76), la Tumba 9 del Cortijo de las Sombras de Frigiliana, Málaga (Arribas y Wilkins, 1969: 228) o la Tumba 4 de Trayamar, también en la provincia de Málaga (Schubart y Niemeyer, 1976: 233).

Más relevante para el análisis de los contextos extremo-occidentales que nos ocupan es la presencia de abalorios de este tipo en la necrópolis de Cádiz, donde parecen ser relativamente frecuentes (Perdigones, Muñoz y Pisano, 1990). Por otra parte, como se expondrá más adelante, los elementos realizados en esta materia prima también se encuentran relativamente bien representados en ambientes indígenas.

Volviendo sin embargo a los materiales portugueses, habría que señalar que su distribución cronológica a lo largo de la Edad del Hierro no es del todo uniforme. La gran mayoría de los elementos documentados provienen, de hecho, de contextos pertenecientes a la I Edad del Hierro regional, y más en concreto de un horizonte cronológico de los siglos VI y V a.n.e.

Por su parte, los elementos de cornalina son raros en horizontes de la II Edad del Hierro, con ejemplos documentados tan solamente en el yacimiento de Mesas do Castelinho, en un contexto fechado entre finales del siglo IV e finales del III a.n.e. (Estrela, 2010: n. 4096),

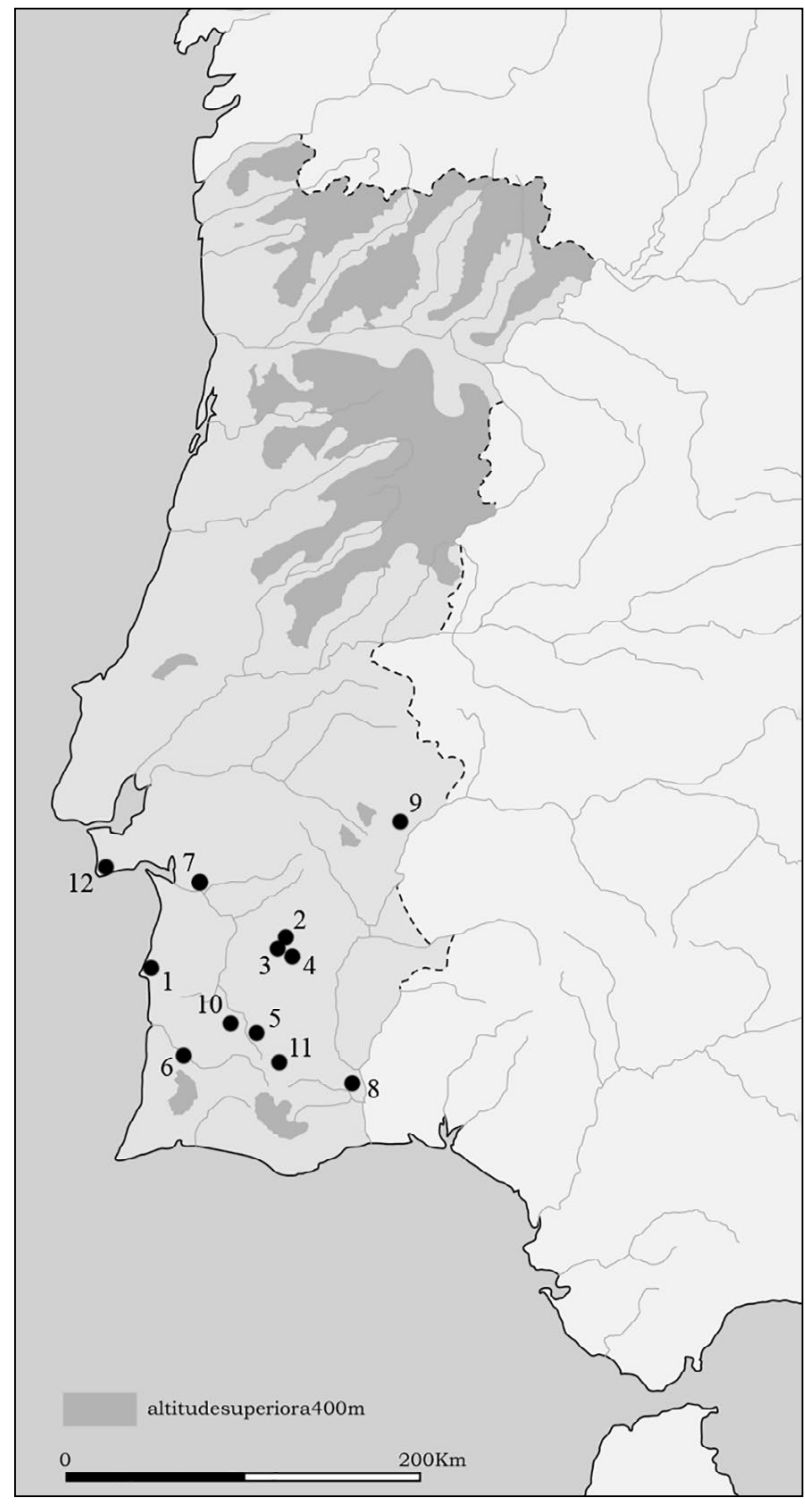

Figura 5: Distribución de los elementos de cornalina de la I Edad del Hierro en el sur de Portugal: 1 - Herdade do Gaio (Sines); 2 - Vinha das Caliças 4 (Beja); 3 - Monte do Bolor 1-2 (Beja); 4 - Quinta do Estácio 6 (Beja); 5 - Fonte Santa (Ourique); 6 Pardieiro (Odemira); 7 - Olival do Senhor dos Mártires (Alcácer do Sal); 8 - Cabeço da Vaca (Alcoutim); 9 - Espinhaço de Cão (Alandroal); 10 - Garvão (Ourique); 11 - Mesas do Castelinho (Almodôvar); 12 - Lapa da Cova (Sesimbra). Ubicaciones aproximadas.

y en el depósito votivo de Garvão, fechado ya muy a finales de ese período (finales del siglo III - inicios del II a.n.e.) (Beirão et al., 1985).

En cuanto a su tipología, pueden una vez más diferenciarse las cuentas de collar de las piezas que más propiamente deben describirse como colgantes. Las cuentas, por su turno, se pueden volver a repartir por los cuatro grandes grupos tipológicos que antes se han mencionado para las piezas del Bronce Final.

Las cuentas bitroncocónicas, muy similares a las del Bronce Final, siguen siendo predominantes desde el punto de vista cuantitativo. Esta tipología suma de 
hecho cinco ejemplares documentados en el «Tesoro» de Herdade do Gaio, Sines (Costa, 1972: fig. 6, nn. 3, 5, 9-10 y 12) (Fig. 6, nn. 1-5), dos más exhumados en la necrópolis de Vinha das Caliças 4, Beja (Gomes, 2014: fig. 3, 2-3; Arruda et al., 2017: 212) (Fig. 6, nn. 7-8) y otro en la necrópolis de Quinta do Estácio 6, Beja (Pereiro, Mataloto y Borges, 2017: fig. 10, 4) (Fig. 6, n. 9). Todos estos yacimientos tienen cronologías centradas en los siglos VI-V a.n.e.

En ambientes grosso modo paralelos desde el punto de vista cronológico podría referirse la presencia de piezas de este tipo en las necrópolis de El Acebuchal (Arribas y Wilkins, 1969: 228) y de La Angorrilla (de la Bandera y Ferrer, 2014: 468 y 470), ambas en la provincia de Sevilla, en la de Valdelagrulla, Badajoz (Menéndez Menéndez et al., 2013: 1020), en la de Cortijo de las Sombras (Arribas y Wilkins, 1969: 228) y en la de Villaricos (Astruc, 1951: 34 y Lám. XV, 19). En contextos no-funerarios se puede citar la presencia de cuentas de cornalina de este mismo tipo en el palacio-santuario de Cancho Roano, Badajoz (Maluquer de Motes, 1983: 145).

Asimismo, un ejemplar también bitroncocónico recogido en la Tumba 4 de la necrópolis de Trayamar (Schubart y Niemeyer, 1976: Lám. 54, 1) pertenece seguramente a una cronología algo más antigua. En La Fonteta las cuentas bitroncónicas están también bien documentadas desde la Fase I (segunda mitad del siglo VIII a.n.e.) hasta la Fase VI (inicios del siglo VI a.n.e.), aunque sean particularmente frecuentes en la Fase II (finales del siglo VIII a inicios del VI a.n.e.) (González Prats, 2014: 343-345).

Por otra parte, se ha documentado un ejemplar adicional en el ya referido depósito de Garvão (Ourique) (Beirão et al., 1985: 94 y fig. 35, n.105) (Fig. 6, n. 11) que debe fecharse ya a finales del siglo III o incluso a inicios del II a.n.e. (Beirão et al., 1985). No disponemos de momento de datos para valorar si el hiato entre estos ejemplos se debe a una efectiva interrupción en la utilización de este tipo de piezas, o más bien a un (probable) sesgo de la investigación.

Una segunda tipología bastante frecuente engloba las cuentas de morfología esférica, presentes en la necrópolis de Olival do Senhor dos Mártires (un ejemplar-Gomes, 2016: 320) (Fig. 6, n. 10) y en el depósito de Garvão (tres ejemplares esféricos achatados - Beirão et al., 1985: 92 y fig. 35, nn. 99-101) (Fig. 6, nn. 16-18). La pieza de Alcácer do Sal desgraciadamente no dispone de contexto, pero las piezas de Garvão, como ya se ha comentado, se pueden fechar con seguridad a finales del siglo III o inicios del II a.n.e.

Las cuentas esféricas, por otra parte, son frecuentes en la necrópolis púnica de Cádiz (Perdigones, Muñoz y Pisano, 1990: 41-44), y están también representadas en las Tumbas del Grupo $\mathrm{C}$ de la necrópolis de Villaricos (Astruc, 1951: 34 y Lám. XV, 18) y en el Tesoro de Ébora (Mata Carriazo, 1973: 351-355), en ambos casos con cronologías de finales del siglo VI o inicios del V a.n.e. Otra cuenta de este mismo tipo recogida en La Fonteta es algo más antigua, al fecharse de la Fase II del yacimiento (finales del siglo VIII - inicios del VII a.n.e.) (González Prats, 2014: 343-345).

La cuenta de este tipo de la Tumba 33 de Puente de Noy podría ser ligeramente más tardía (Molina Fajardo, Ruiz Fernández y Huertas Jiménez, 1982: 76), tal y como las del pecio de El Sec, fechadas con seguridad en la primera mitad del siglo IV a.n.e. (Arribas et al., 1987: 593).

Las cuentas de morfología cilíndrica cuentan también con una representación relativamente expresiva. Así, en el «Tesoro» de Herdade do Gaio se ha recuperado una cuenta de morfología cilíndrica abombada (Costa, 1972: fig. 6, n.4) (Fig. 6, n. 6). También en la Tumba 4 de la necrópolis de Fonte Santa (Ourique) se ha recogido una cuenta descrita como oblonga (Beirão, 1986: 71), que podría corresponder a esta misma tipología. Ambos yacimientos cuentan con cronologías entre el siglo VI avanzado y el V a.n.e.

Las piezas cilíndricas siguen sin embargo presentes ya en la II Edad del Hierro regional, habiéndose documentado una pieza de este tipo en el yacimiento de Mesas do Castelinho, en niveles fechados entre finales del siglo IV y finales del III a.n.e. (Estrela, 2010: n. 4096), bien como en el ya citado depósito votivo de Garvão (Beirão et al., 1985: 92 y fig. 35, n. 102) (Fig. 6, n. 15).

Las cuentas de cornalina cilíndricas se han documentado en la necrópolis de Cádiz (Perdigones, Muñoz y Pisano, 1990: 29 y fig. 37, 5), en el santuario de La Algaida, también en Cádiz (Ruano Ruiz, Moreno y Pellús, 1996; López Amador y Ruiz Gil, 2010), en la Tumba 41 de la necrópolis de La Angorrilla (de la Bandera y Ferrer, 2014: 472), en el Tesoro de Ébora (Mata Carriazo, 1973: 351-355) así como en La Fonteta, en su Fase VI (inicios del siglo VI a.n.e.) (González Prats, 2014: 343-345), y en Ibiza (Almagro-Gorbea et al., 2004: 167).

Por último, las cuentas de tipología discoide están también documentadas durante la Edad del Hierro, aunque sólo en momentos muy avanzados de este período. De hecho, esta tipología de cuentas sólo se ha documentado en el ya citado depósito de Garvão, donde se identificaron tres ejemplares (Beirão et al., 1985: 92-94 y fig. 35, nn. 103-104 y 106) (Fig. 6, nn. 12-14), fechables como las demás piezas de este depósito a finales del siglo III o inicios del II a.n.e.

Cuentas de este mismo tipo se han recuperado también en contextos algo más antiguos, como el santuario de La Algaida (Ruano Ruiz, 1996; López Amador y Ruiz Gil, 2010) o las tumbas del Grupo C de la necrópolis de Villaricos (Astruc, 1951: 34 y Lám. XV, 17).

Finalmente, cabría señalar la existencia de algunas cuentas de difícil adscripción tipológica. La identificación de una cuenta de la necrópolis de Mealha Nova (Ourique), descrita únicamente como teniendo forma de «grano de granada» (Dias, Beirão y Coelho, 1971: 178), por ejemplo, resulta bastante compleja dada la 


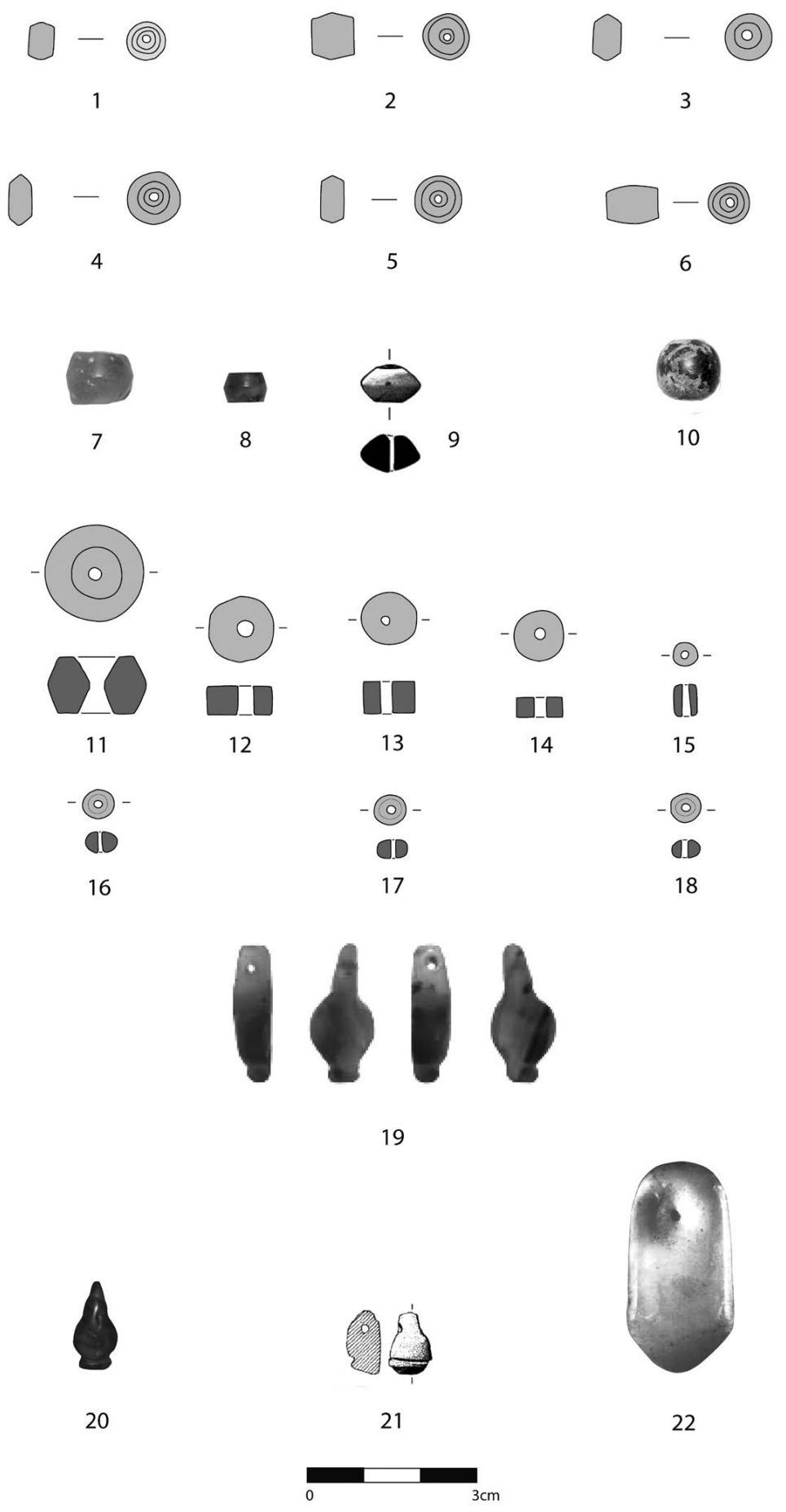

Figura 6: Elementos de cornalina de la Edad del Hierro: 1-6 - Herdade do Gaio (seg. Costa, 1972); 7-8 - Vinha das Caliças 4 (Arruda et al., 2017); 9 - Quinta do Estácio 6 (Pereiro, Mataloto y Borges, 2017); 10 - Olival do Senhor dos Mártires (Gomes, 2016); 11-18 Garvão (Beirão et al., 1985); 19 - Monte do Bolor 1-2 (Soares et al., 2017); 20 - Vinha das Caliças 4 (Arruda et al., 2017); 21 - Cabeço da Vaca (Cardoso y Gradim, 2006); 22 - Pardieiro (Beirão, 1990).

escasez de elementos de juicio. De igual modo, y junto con la pieza de Fonte Santa antes mencionada, se ha recuperado una segunda cuenta de cornalina, cuya tipología lamentablemente tampoco se ha especificado (Beirão, 1986: 71).

Por otra parte, cabría señalar que en el ya mencionado yacimiento de Mesas do Castelinho se han documentado varios ejemplares adicionales de cuentas de cornalina, que sin embargo provienen de contextos secundarios de cronología republicana, imperial e incluso medieval (Estrela, 2010: tab. 19). No es improbable que el uso original de al menos algunas de esas piezas remonte a la Edad del Hierro, como sugiere la responsable de su estudio (Estrela, 2010: tab. 19), pero al haberse recuperado en contextos posteriores tampoco se puede excluir de forma tajante su pertenencia a 
cronologías más tardías, por lo que no se han recopilado en el presente estudio.

Hay además una referencia a la presencia de cuentas de cornalina de tipo y en número no especificados en la cueva-santuario de Lapa da Cova, en Sesimbra (Soares, 2012: 90; 100). Estas piezas se encuentran al parecer asociadas a abundantes abalorios de otras materias primas exógenas, en particular el vidrio (Soares, 2012: 90; 100). Estos materiales se encuentran todavía en estudio, y su publicación seguramente añadirá nuevos e importantes datos para la discusión del tema tratado en esta contribución.

En cuanto a los colgantes, el grupo tipológico más numeroso es una vez más el de los colgantes fitomorfos, similares en todo a los del Bronce Final anteriormente comentados. En contextos de la Edad del Hierro se han documentado tres ejemplares pertenecientes a este tipo, provenientes de las necrópolis de Vinha das Caliças 4 (Gomes, 2014: fig. 3, 1; Arruda et al., 2017: 212) (Fig. 6, n. 20), de Monte do Bolôr 1-2 (Soares et al., 2017: 281 y fig. 11, n. 1) (Fig. 6, n. 19) y de Cabeço da Vaca (Alcoutim) (Cardoso y Gradim, 2006: 213 y figs. 15, n. 1 y 16, n. 1), este último de factura al parecer menos cuidada (Fig. 6, n. 21). De forma general, y teniendo en consideración sus contextos, todas estas piezas pueden adscribirse al siglo VI a.n.e., e incluso más específicamente a su segunda mitad.

La reaparición de este tipo de colgantes en esta etapa relativamente avanzada de la I Edad del Hierro no deja de ser sorprendente, sobre todo debido a su total identidad formal con las piezas del Bronce Final (excepto quizás en el caso de la pieza de Cabeço da Vaca, de aspecto más tosco). Por ello, no se puede descartar que las piezas exhumadas en contextos más recientes correspondan a elementos llegados durante los momentos finales de la Edad del Bronce, pero que se mantienen en uso como heirlooms (Lillios, 1999) hasta amortizarse durante la I Edad del Hierro, período en el cual el ámbito funerario adquiere una renovada importancia en la representación del poder y del estatuto social.

Sin embargo, y a pesar de lo sugerente que podría resultar esta lectura, la verdad es que los colgantes fitomorfos del tipo en discusión también siguen presentes en el Mediterráneo Oriental ya durante la Edad del Hierro. De hecho, este tipo de abalorio sigue documentándose de forma puntual en Egipto hasta la Baja Época (Phillips, 2008: 141).

En el área siropalestina también se documentan piezas de este tipo en la Edad del Hierro, como por ejemplo en Megiddo, Israel, donde los ejemplares conocidos son sin embargo más antiguos que sus congéneres occidentales (siglos X-IX a.n.e.) (Hall, 2016: pl. 10). No obstante, la pieza recogida en la Tumba $n$. 1 de la necrópolis norte de Achziv, también en Israel, proveniente de un contexto con una cronología de los siglos IX a VII a.n.e. (Mazar, 2004: 92-93), se acerca más cronológicamente a las piezas en estudio.
Por otro lado, cabría señalar, ya en contexto peninsular, la presencia de uno de estos colgantes entre los materiales que componen el Tesoro de Ébora (Mata Carriazo, 1973: 354-355 y figs. 261-262), fechable entre finales del siglo VI e inicios del V a.n.e. (Torres Ortiz, 2008: 78).

Así, es posible que los colgantes fitomorfos recogidos en contextos de la I Edad del Hierro del sur de Portugal hayan efectivamente llegado en momentos cercanos al de su deposición en las tumbas de las necrópolis antes mencionadas. Los elementos importados de origen mediterráneo son además muy frecuentes en las tumbas de este período (Gomes, 2014; 2016), especialmente en el interior (Jiménez Ávila, 2017).

No parece por ende descabellado pensar que estos abalorios, más que elementos heredados de un período anterior, puedan efectivamente haber formado parte de los mismos flujos comerciales que en estos momentos han traído hacia el Extremo Occidente los amuletos de tipo egipcio o las abundantes cuentas de vidrio y de fayenza que se vienen documentando en estos contextos sepulcrales (Gomes, 2014; 2016; contribuciones en Jiménez Ávila, 2017).

Aparte de estas piezas fitomorfas, el otro único colgante de cornalina bien conocido del sur del territorio portugués corresponde a una pieza de forma amigdaloide recogida en la Tumba 1 de la necrópolis de Pardieiro (Odemira) (Beirão, 1990: 111 y fig. 8) (Fig. 6, n. 22), conjunto funerario cuya cronología se centraría del mismo modo entre el siglo VI y el V a.n.e. Este colgante formaría parte de un collar complejo, ya que en la misma tumba se documentaron cuentas de oro, vidrio y ámbar, además del engaste de un escarabeo, no preservado (Beirão, 1990: 111).

Finalmente, se refiere la presencia de un colgante de cornalina en el yacimiento de Espinhaço de Cão (Redondo) (Calado, Mataloto y Rocha, 2007: 149) cuya tipología, sin embargo, no se ha especificado todavía. De todos modos, la ocupación de este yacimiento parece cubrir un período entre finales del siglo VII e inicios del V a.n.e. (Calado, Mataloto y Rocha, 2007: 151).

\section{DISCUSIÓN Y REFLEXIONES FINALES}

Como se ha podido apreciar en las páginas anteriores, y a pesar de las muchas limitaciones que persisten a la hora de valorar estos materiales, los datos disponibles sobre la difusión de los abalorios de cornalina en la Protohistoria del sur de Portugal son ya significativos y permiten realizar una serie de valoraciones preliminares de conjunto.

Desde luego, una primera lectura que puede extraerse de la información compulsada se refiere a la distribución cronológica de las piezas de cornalina, marcada como pudo apreciarse por ciertas fluctuaciones (Fig. 7). De hecho, y con los datos disponibles, se puede afirmar que los primeros abalorios de cornalina 


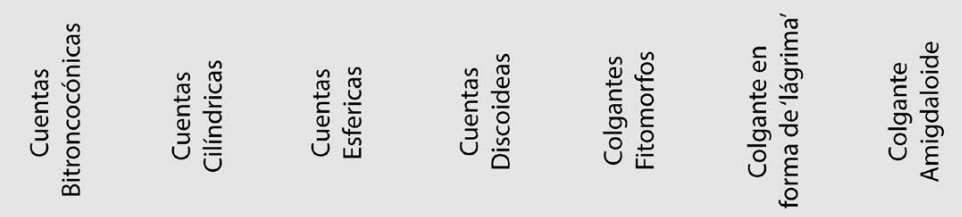

1250

1200

1150

1100

1050

1000

950

900

850

800

750

700

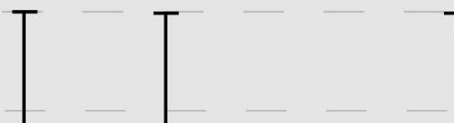

650

600

550

500

450

400

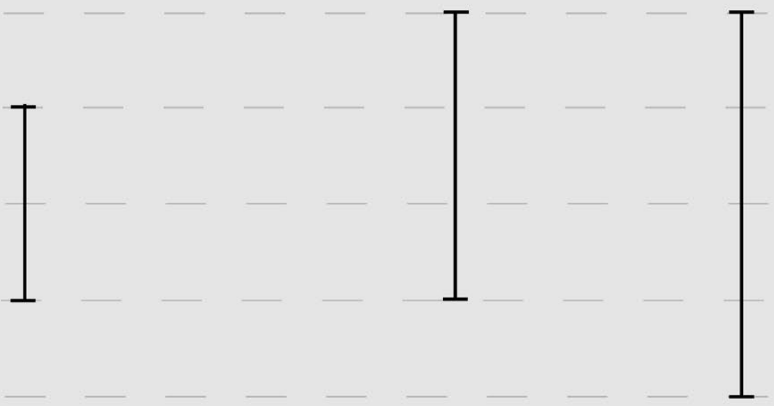

350

300

250

200

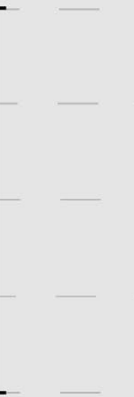

.

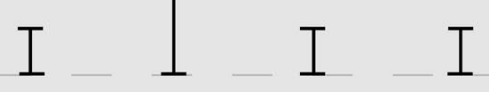

Figura 7: Parámetros cronológicos de los elementos de cornalina estudiados. 
llegaron al territorio portugués durante una etapa plena del Bronce Final, aunque no pueda precisarse la fecha exacta de dicha llegada.

Sin embargo, estos elementos más precoces parecen ser relativamente escasos comparados con los que se pueden atribuir a un horizonte terminal del Bronce Final regional, ya en paralelo con la primera presencia fenicia en el sur peninsular. El caso de estudio de Castro dos Ratinhos es significativo: la mayoría de las piezas allí exhumadas -ocho o nueve cuentas de las 13 o 14 documentadas- provienen de contextos tardíos, fechables entre finales del siglo IX y mediados del VIII a.n.e. (Berrocal-Rangel y Silva, 2010: 316).

Si además se tomara como regla general la fecha tardía de las cuentas bitroncocónicas de Castro dos Ratinhos -hipótesis avalada además por la cronología de otros conjuntos y yacimientos peninsulares (Ruiz Gil y López Amador, 2004; Lorrio, 2008: 290-291)-, habría igualmente que fechar las piezas de este tipo de los demás yacimientos portugueses en esos momentos finales de la Edad del Bronce. Ello reforzaría la imagen de un incremento en la llegada de los abalorios de cornalina durante esta etapa.

Sin embargo, y tras ese incremento, probablemente relacionado con los primeros asomos del comercio fenicio en la región, parece producirse un quiebro en la circulación de estos elementos, siendo escasos, por no decir nulos, los registros que pueden fecharse sin problemas en pleno siglo VII a.n.e.

$\mathrm{Si}$ en los territorios del interior este hecho no parece sorprendente, ya que éste es un momento de marcada desestructuración de las comunidades que los ocupan, resulta algo más inusitada la ausencia de estos abalorios en contextos litorales. Quizás se deba achacar este hecho al persistente desconocimiento de las necrópolis asociadas a esos contextos (Arruda, Covaneiro y Cavaco, 2008; Gomes, 2016), ya que la documentación posterior parece indicar que estos abalorios están presentes sobre todo en contextos sepulcrales.

De todos modos, durante los siglos VI y V a.n.e. se asiste a un notable resurgimiento de los abalorios de cornalina, que aunque no tan frecuentes como los adornos de otras materias primas exóticas (vidrio, fayenza, ámbar...) están presentes en distintas necrópolis pertenecientes a los principales grupos funerarios de estos momentos en el sur de Portugal (Gomes, 2014; 2016: con bibliografía).

Parece evidente que, más que a meros criterios comerciales o de gusto, existen factores específicamente arqueográficos que justifican esta situación. La inversión en la investigación sobre la I Edad del Hierro en esta región no es, de hecho, comparable a la que se dedicó a los momentos anteriores o posteriores, lo cual en parte justifica el mayor volumen de datos para estos momentos.

No obstante, la creciente visibilidad del registro funerario durante este período o la potente inversión de medios por parte de las comunidades locales en la adquisición de elementos de atuendo y de adorno que en última instancia terminan depositados en las tumbas no son un mero resultado de los sesgos de la investigación, sino que se pueden considerar como características relevantes de las fórmulas sociales desarrolladas en estos momentos por las comunidades locales.

El incremento de los abalorios de cornalina en esta etapa puede por ende considerarse como algo más que un sesgo estadístico, y constituye un reflejo más de la búsqueda por parte de las comunidades locales de elementos de naturaleza exótica destinados a enfatizar su poder y su estatuto social en un marco social que aparenta haber sido fuertemente competitivo.

De todos modos, y tras este período, se verifica de nuevo una marcada reducción de los abalorios de cornalina, que se mantienen prácticamente ausentes a lo largo de la II Edad del Hierro regional. En este caso sí que cabría pensar que ello se debe, al menos en parte, a la escasez de proyectos de investigación sobre este período en la mayor parte del territorio meridional portugués.

De hecho, resulta difícil pensar que un caso como el de Mesas do Castelinho, donde los adornos de cornalina pueden haber sido relativamente frecuentes (véanse, sin embargo, las consideraciones supra), o sobre todo el de Garvão, donde efectivamente lo son, sean casos aislados. Quizás el futuro desarrollo de programas de excavación en los grandes poblados y en las escasas necrópolis conocidas de este período permita cambiar y equilibrar el panorama dibujado en esta contribución.

Otro aspecto merecedor de algunas breves notas hace referencia a la repartición territorial de los abalorios estudiados. Hay que señalar, para el Bronce Final, que los elementos de cornalina presentan una distribución claramente interior, que parece a priori difícil de compatibilizar con un origen exógeno que conllevaría una introducción por vía marítima y, en consecuencia, litoral.

Sin embargo, éste es un patrón frecuente para el Sur e incluso para el centro de Portugal, donde los elementos mediterráneos o de tipo mediterráneo casi siempre presentan distribuciones predominantemente interiores (Arruda, 2008; Vilaça, 2008). Ese hecho podría resultar de lógicas competitivas de intercambio de dones en que las élites de las comunidades litorales buscarían elementos exóticos sobre todo para emplearlos como regalos para sus congéneres del interior, que por su parte retribuirían dichos regalos con elementos de valor social equivalente pero más difíciles de documentar en el registro arqueológico (Gomes, 2015).

Por otra parte, durante la I Edad del Hierro se aprecia un mayor equilibrio en la distribución de estos abalorios, que sin embargo siguen siendo más frecuentes en los territorios del interior. En tales casos, la explicación debería quizás buscarse en la naturaleza predominantemente rural de las comunidades de dichos territorios. 
De hecho, en ese marco rural las relaciones sociales, no mediatizadas por las instituciones urbanas que empiezan a emerger y a consolidarse en las áreas litorales, siguen caracterizándose por una fuerte competencia intra e intergrupal, que se manifiesta en la ostentación exterior de la riqueza y del estatuto social (Gomes, 2014; 2016). La presencia de grandes cantidades de abalorios exóticos constituye una expresión de esas lógicas de ostentación.

En cuanto a la II Edad del Hierro, la base documental con la que contamos es de momento demasiado escueta como para permitir cualquier discusión fundamentada sobre la distribución geográfica de los elementos de cornalina. De hecho, hay que considerar que la distribución interior que se aprecia, basada en dos únicas ocurrencias, carece de gran significado estadístico, sobre todo cuando se considera el desconocimiento casi total de la gran mayoría de los centros de la II Edad del Hierro del litoral.

Llegados a este punto de la discusión, cabría considerar, aunque de forma superficial, el tema de la procedencia de las piezas aquí estudiadas, cuestión que como se ha podido apreciar se encuentra subyacente a los diversos temas antes abordados.

A lo largo de este estudio se ha asumido, como lo hacen otros autores (Martín de la Cruz, 2004; Martín de la Cruz et al., 2005; Torres Ortiz, 2008), que estas piezas tienen una origen exógeno, extra-peninsular, puesto que todavía no se han documentado fuentes de cornalina en la Península Ibérica y se siguen acumulando los datos tipológicos y contextuales que abogan a favor de un origen foráneo, muy probablemente oriental. Sin embargo, hay que reconocer que los datos específicos que se desprenden de la documentación portuguesa no arrojan demasiada luz a la hora de determinar, o al menos de acotar, ese origen.

Quizás la herramienta con mayores posibilidades de zanjar el problema de la procedencia de estas piezas sea su estudio analítico. Sin embargo, y como ya se ha comentado, los análisis de piezas de cornalina siguen siendo por lo general muy escasos.

En el caso portugués contamos, no obstante, con análisis por difracción de RX para algunas piezas del Bronce Final, en concreto las de Castro dos Ratinhos, de Álamo y de Salsa 3 (Gonçalves y Soares, 2010; Gonçalves et al., 2011), que entre otros aspectos han confirmado la identificación de la materia prima como cornalina, demostrando además la uniformidad de la composición de las piezas estudiadas, lo cual sugiere un origen común.

Los resultados de los análisis de estas piezas parecen además comparables a los que se obtuvieron para diversas piezas andaluzas (Barrios Neira et al., 2004) y alicantinas (Martínez Mira y Vilaplana Ortego, 2014: 863-867). Esto podría indicar que las piezas de cornalina que circulan en el sur peninsular durante las etapas finales de la Edad del Bronce provienen de una misma fuente.
Sin embargo, y lamentablemente, no contamos de momento con análisis comparables sobre los paralelos extrapeninsulares de las piezas en cuestión, con lo cual sigue siendo imposible determinar con exactitud la proveniencia de los abalorios de cornalina peninsulares, aunque por razones tipológicas ya comentadas parezca muy probable un origen egipcio.

Por otra parte, y con respecto a los ejemplares de la Edad del Hierro, seguimos sin disponer de estudios analíticos que permitan comparar los materiales entre sí y con sus antecedentes del Bronce Final, laguna que se espera superar en un futuro próximo. Sin embargo, considerada su tipología, que presenta notables similitudes con la de sus congéneres más antiguos, es muy probable que el centro abastecedor siga siendo el mismo, al menos durante la I Edad del Hierro.

Debe además recordarse que durante este período la cornalina no sería el único elemento de producción egipcia en llegar al Extremo Occidente, ya que en las mismas necrópolis $-\mathrm{y}$ a veces incluso en las mismas tumbas- donde se recogió buena parte de las piezas estudiadas se documentan otros abalorios de probable manufactura egipcia, incluidos cuentas de fayenza (Arruda et al., 2017; Soares et al., 2017) y amuletos (Almagro Gorbea y Torres Ortiz, 2009).

Estos materiales, por su parte, constituyen apenas una pequeña porción de los materiales egipcios difundidos en la Península Ibérica a través del comercio fenicio (Padró, 1980-1985; 1995; García Martínez, 2002).

En cuanto a las vías de circulación de estos elementos, no parece de momento posible especificar los agentes responsables de la distribución de los ejemplares más antiguos del Bronce Final, cuya fecha sigue siendo demasiado imprecisa. La hipótesis avanzada por algunos autores de que dichas piezas se difunden por vía del comercio chipriota (Martín de la Cruz y Vera Rodríguez, 2004: 16; Torres Ortiz, 2008: 78), aunque difícil de demostrar de forma tajante, parece de momento la más probable.

Sin embargo, parece muy probable que la difusión de estos adornos a partir de los finales del siglo IX a.n.e. se produzca ya en el marco de la red comercial fenicia $\mathrm{y}$, posteriormente, púnica. En favor de esta hipótesis se puede recordar, entre otros datos, la presencia muy significativa de elementos de cornalina en ambientes funerarios fenicios y púnicos (véase supra).

Antes de finalizar esta valoración global sobre los abalorios de cornalina del sur de Portugal no puede obviarse el tema de sus contextos sociales de uso, ya aflorado en algunos casos en las páginas anteriores. Sin embargo, hay que reconocer que para el Bronce Final los datos disponibles sobre este tema específico son bastante limitados.

Una vez más, el único contexto que puede quizás aportar alguna luz sobre esta cuestión es el Castro dos Ratinhos. En este yacimiento, los elementos de cornalina se han documentado esencialmente dispersos por la acrópolis, un área claramente diferenciada en el 
contexto del poblado y que puede interpretarse como un espacio de elite.

Podría por eso plantearse una asociación preferencial entre estos elementos exóticos y los estamentos más destacados de la sociedad, aunque al no haberse excavado otras zonas domésticas del yacimiento dicha asociación no puede en absoluto considerarse clara ni definitiva.

En cuanto a los materiales de la I Edad del Hierro, la situación resulta algo más clara. De hecho, la totalidad de las piezas de cornalina de este período se ha recuperado en contextos sepulcrales, documentando, como ya se afirmó, que estos abalorios exóticos se movilizan en discursos de ostentación y distinción social proyectados sobre todo en el ámbito de la muerte.

En este contexto, se pueden señalar algunos casos expresivos en que los elementos de cornalina se asocian a conjuntos funerarios de particular riqueza, como el Tesoro de Herdade do Gaio (Costa, 1972), la Tumba 4 de la necrópolis de Fonte Santa (Beirão, 1986: 71), la Tumba 48 de Vinha das Caliças 4 (Arruda et al., 2017: fig. 6) o la Tumba 3 de Quinta do Estácio 6 (Pereiro, Mataloto y Borges, 2017: 319). Estos ejemplos, sumados a la escasez de la cornalina comparada con materias primas como el vidrio, la fayenza o incluso el ámbar, podría estar indicando una considerable valoración social de estos abalorios.

Tras considerar todos estos aspectos, queda claro que la discusión desarrollada en las páginas anteriores -que más que un punto de llegada se ha planteado como una valoración inicial de un tema poco trabajado-, deja muchas cuestiones concretas por aclarar. Sin embargo, los datos que dicha discusión sí ha podido aportar permiten afirmar que el estudio de los abalorios de cornalina se cruza con el análisis de los procesos sociales del Bronce Final y de la Edad del Hierro regionales de formas muy interesantes y pertinentes, lo cual en sí mismo justifica una mayor atención a estos elementos en la investigación futura.

Dicha investigación deberá además seguir valorando contextualmente a los elementos «exóticos»y analizando las formas como se han incorporado localmente en discursos y estrategias de representación cuya reconstrucción ofrece un enorme potencial para una comprensión más profunda y consistente de los procesos sociales locales e regionales durante la Protohistoria del suroeste peninsular.

\section{REFERENCIAS}

Adler, W. (1996). Die spätbronzezeitlich Pyxiden in Gestalt von Wasservögeln. En R. Hachmann (Ed.). Kamid el-Loz 16. Schatzhaus'Studien (pp. 27-117). Bonn: Habelt.

Alarashi, H. (2016). Butterfly Beads in the Neolithic Near East: Evolution, Technology and Socio-cultural implications. Cambridge Archaeological Journal, 26(3), 493-512. DOI: https://doi.org/10.1017/S0959774316000342
Almagro-Gorbea, M., Casado, D., Fontes, F., Mederos, A. y Torres, M. (2004). Prehistoria. Antiguëdades Españolas I. Madrid: Real Academia de la Historia.

Almagro-Gorbea, M. y Torres Ortiz, M. (2009). Los escarabeos fenicios de Portugal. Un estado de la cuestión. Estudos Arqueológicos de Oeiras, 17, 521-554.

Arnaud, J. M. (1979). Corôa do Frade. Fortificação do Bronze final dos arredores de Évora. Escavações de 19711972. Madrider Mitteilungen, 20, 56-100.

Arribas, A., Trías, G., Cerdà, D. y de Hoz, J. (1987). El Barco de El Sec (Calvià, Mallorca). Estudio de los materiales. Calvià: Ajuntament de Calvià.

Arribas, A. y Wilkins, J. (1969). La necrópolis fenicia del Cortijo de las Sombras (Frigiliana, Málaga). Pyrenae, 5, 185-244.

Arruda, A. M. (2008). Estranhos numa terra (quase) estranha: os contactos pré-coloniais no Sul do território actualmente português. En S. Celestino, N. Rafel, y X.-L. Armada (Eds.). Contacto cultural entre el Mediterráneo y el Atlántico (siglos XII-VIII ane). La precolonización a debate (pp. 355-370). Madrid: Consejo Superior de Investigaciones Científicas.

Arruda, A. M., Barbosa, R., Gomes, F. B. y Sousa, E. de (2017). A necrópole da Vinha das Caliças (Beja, Portugal). En J. Jiménez Ávila (Ed.). Sidereum Ana III. El Río Guadiana y Tartessos (pp. 187-225). Mérida: Consorcio Ciudad Monumental Histórico-Artística e Arqueológica de Mérida.

Arruda, A. M., Covaneiro, J. y Cavaco, S. (2008). A Necrópole da Idade do Ferro do Convento da Graça, Tavira. Xelb, 8, 117-135.

Astruc, M. (1952). La necrópolis de Villaricos. Madrid: Ministerio de Educación Nacional.

de la Bandera, M. ${ }^{\text {a }}$ L. y Ferrer Albelda, E. (2014). Las joyas y adornos personales. En Á. Fernández Flores, A. Rodríguez Azogue, M. Casado Ariza y E. Prados Pérez (Coords.). La Necrópolis de Época Tartésica de La Angorrilla, Alcalá del Río, Sevilla (pp. 429-476). Sevilla: Universidad de Sevilla.

Barrios Neira, J., Montealegre Contreras, L., Martín de la Cruz, J. C. e Ibarra de Dios, F. J. (2004). Análisis de microscopía y difracción de RX sobre colgantes y cuentas. Revista de Prehistoria, 3, 14-16.

Beck, H. C. (1928). Classification and nomenclature of beads and pendants. Archaeologia, 77, 1-76.

Beirão, C. de M. (1986). Une Civilisation Protohistorique du Sud du Portugal (Ier Âge du Fer). Paris: Éditions du Boccard.

Beirão, C. de M. (1990). Epigrafia da Idade do Ferro do Sudoeste da Península Ibérica. Novos dados arqueológicos. Estudos Orientais, I, 107-118.

Beirão, C. de M., Silva, C. T. da, Soares, J., Gomes, M. V., y Gomes, R. V. (1985). Depósito votivo da II Idade do Ferro de Garvão. Notícia da primeira campanha de escavações, $O$ Arqueólogo Português, IV(3), 45-135.

Bernabò Brea, L. y Cavalier, M. (1960). Meligunís Lipara I. Palermo: Flaccovio. 
Berrocal-Rangel, L. y Silva, A. C. (2010). O Castro dos Ratinhos (Barragem do Alqueva, Moura). Escavações num povoado proto-histórico do Guadiana, 2004-2007. Lisboa: Museu Nacional de Arqueologia.

Brunet, O. (2009). Bronze and Iron Age carnelian bead production in the UAE and Armenia: new perspectives. Proceedings of the Seminar for Arabian Studies, 39, 57-68.

Buchholz, H.-G. y Karageorghis, V. (1973). Prehistoric Greece and Cyprus. An Archaeological Handbook. Londres: Phaidon.

Calado, M., Barradas, M. y Mataloto, R. (1999). Povoamento Proto-histórico no Alentejo Central. En Actas do Congresso de Proto-História Europeia, Vol. I (pp. 363-386). Guimarães: Sociedade Martins Sarmento.

Calado, M., Mataloto, R. y Rocha, A. (2007). Povoamento Proto-Histórico na Margem Direita do Regolfo do Alqueva (Alentejo, Portugal). En A. Rodríguez Días y I. Pavón Soldevila (Eds.). Arqueología de la Tierra. Paisajes rurales de la protohistoria peninsular (pp. 129-179). Cáceres: Universidad de Extremadura

Cardoso, J. L. (2004). Uma tumulação do final do Bronze Final/inícios da Idade do Ferro no sul de Portugal: a tholos do Cerro do Malhanito (Alcoutim). En R. Vilaça y M. ${ }^{a}$ C. Lopes (Coords.). O Passado em Cena: Narrativas e Fragmentos. Miscelânea Oferecida a Jorge de Alarcão (pp. 193-223). Coimbra: Centro de Estudos Arqueológicos das Universidades de Coimbra e do Porto.

Cardoso, J. L. y Cardoso, G. (1996). O povoado do Bronze Final do Alto das Cabeças (Leião, Oeiras). Estudos Arqueológicos de Oeiras, 6, 351-359.

Cardoso, J. L. y Gradim, A. (2006). A Necrópole da Idade do Ferro de Cabeço da Vaca (Alcoutim). Xelb, 6, 203-226.

Caubet, A. y Yon, M. (2004). Quelques perles de cornaline. En A. M. Maeir y P. de Miroschedji (Eds.). «I Will Speak The Riddle Of Ancient Times». Archaeological and Historical Studies in Honor of Amihai Mazar on the Occasion of His Sixtieth Birthday (pp. 137-147). Warsaw: Eisenbrauns.

Costa, J. M. da (1972). O tesouro púnico-tartéssico do Gaio. En Actas das II Jornadas da Associação dos Arqueólogos Portugueses (pp. 97-120). Lisboa: Associação dos Arqueólogos Portugueses.

Courtois, J.-C. (1984). Alasia III: Les objets des niveaux stratifiés d'Enkomi. Fouilles Schaeffer (1947-1970). Paris: Éditions Recherches sur les Civilizations.

Daviau, P. M. M. y Steiner, M. L. (Eds.). (2017). A Wayside Shrine in Northern Moab: Excavations in the Wadi AthThamad. Oxford: Oxbow Books.

Dias, M. ${ }^{a}$ M. A., Beirão, C. de M. y Coelho, L. (1971). Duas necrópoles da Idade do Ferro no Baixo-Alentejo: Ourique. (Notícia preliminar). O Arqueólogo Português, III(4), 175-219.

Escacena Carrasco, J. L. (2008). Cantos de sirena: la precolonización fenicia de Tartessos. En S. Celestino, N. Rafel y X.-L. Armada (Eds.). Contacto cultural entre el
Mediterráneo y el Atlántico (siglos XII-VIII ane). La precolonización a debate (pp. 301-322). Madrid: Consejo Superior de Investigaciones Científicas.

Estrela, S. (2010). Os níveis fundacionais da Idade do Ferro de Mesas do Castelinho (Almodôvar): os contextos arqueológicos na (re)construção do povoado. (Tesis de Máster). Universidad de Lisboa. Lisboa. Recuperado de: http://repositorio.ul.pt/handle/10451/3009

Fernández, J. H. y Padró, J. (1982). Escarabeos del Museo Arqueologico de Ibiza. Ibiza: Museo Arqueológico de Ibiza.

García Martínez, M. A. (2002). Documentos prerromanos de tipo egipcio de la vertiente atlántica hispano-mauritana. Montpellier: Université Paul Valéry.

Gibson, C., Correia, V. H., Burgess, C. B. y Boardman, S. (1998). Alto do Castelinho da Serra (Montemor-o-Novo, Évora, Portugal). A preliminary report on the excavations at the Late Bronze Age to Medieval site, 1990-1993. Journal of Iberian Archaeology, 0, 189-244.

Gomes, F. B. (2014). Importações mediterrâneas em contextos «Pós-Orientalizantes» do Sul de Portugal (séculos VI-IV a.n.e.). Onoba, 2, 27-44.

Gomes, F. B. (2015). The West Writes Back: cultural contact and identity discourses in the Late Bronze Age and Early Iron Age of Southern Portugal. En A. Babbi, F. Bubenheimer-Erhart, B. Marin-Aguilera, y S. Mühl (Eds.). The Mediterranean Mirror. Cultural Contacts in the Mediterranean Sea between 1200 and 750 B.C. (pp. 305317). Mainz: RGZM.

Gomes, F. B. (2016). Contactos culturais e discursos identitários na I Idade do Ferro do Sul de Portugal (séculos VIII a V a.n.e.): leituras a partir do registo funerário. (Tesis doctoral). Universidad de Lisboa. Lisboa. Recuperado de: http:// repositorio.ul.pt/handle/10451/25042

Gonçalves, A, P. y Soares, A. M. (2010). As «contas de colar» dos Ratinhos - I. As contas em pedra, análise por Difracção de Raios X. En L. Berrocal-Rangel y A. C. Silva (Dirs.). $O$ Castro dos Ratinhos (Barragem do Alqueva, Moura). Escavações num povoado proto-histórico do Guadiana, 2004-2007 (pp. 389-392). Lisboa: Museu Nacional de Arqueologia.

Gonçalves, A. P., Soares, A. M., Silva, A. C., y BerrocalRangel, L. (2011). Stone Beads from Late Bronze Age and Early Iron Age Settlements from South-Western Portugal: Analyses by X-Ray Diffraction. En I. Turbanti-Memmi (Ed.). Proceedings of the 37th International Symposium on Archaeometry (pp. 227-231). DOI: https://doi. org/10.1007/978-3-642-14678-7_32

González Prats, A. (Coord.). (2014). La Fonteta-2. Estudio de los materiales arqueológicos hallados en la colonia fenicia de la actual desembocadura del río Segura (Guardamar, Alicante). Alicante: Universidad de Alicante.

Groman-Yaroslavski, I. y Bar-Yosef, D. (2015). Lapidary technology revealed by functional analysis of carnelian beads from the early Neolithic site of Nahal Hemar Cave, southern Levant. Journal of Archaeological Science, 58, 77-88. DOI: https://doi.org/10.1016/j.jas.2015.03.030 
Hall, E. (2016). Hoarding at Tel Megiddo in the Late Bronze Age and Iron Age I. (Tesis de Máster). Universidad de Tel Aviv. Tel Aviv. Recuperado de: https://www.academia. edu/27414292/Hoarding at Tel Megiddo in the Late Bronze_Age_and_Iron_Age_ I

Harden, D. (1962). The Phoenicians. Bristol: Praeger.

Harrell, J. A. y Storemyr, P. (2009). Anciente Egyptian quarries - an illustrated overview. En N. Abu-Jaber, E. G. Bloxam, P. Degryse y T. Heldal (Eds.). QuarryScapes: ancient stone quarry landscapes in the Eastern Mediterranean (pp. 7-50). Oslo: Geological Survey of Norway.

Hepper, N. (1990). Pharaoh's Flowers: The Botanical Treasures of Tutankhamun. Londres: Royal Botanical Gardens.

Iakovides, S. (1969). Excavations of the necropolis of Perati. Los Angeles: University of California.

Ingram, R. S. (2005). Faience and glass beads from the Late Bronze Age shipwreck at Uluburun. (Tesis de Máster). Universidad de Texas A\&M. College Station. Recuperado de: http://oaktrust.library.tamu.edu/handle/1969.1/2289

Inizan, M.-L. (1999). La cornaline de l'Indus et la voie du Golfe au IIIe millénaire. En A. Caubet (Dir.). Cornaline et pierres précieuses. La Mediterrannée, de l'Antiquité à l'Islam (pp. 125-138). Paris: Réunion des Musées Nationaux.

Inizan, M.-L. (2000). Importation de cornalines et agates de l'Indus en Mésopotamie. Le cas de Suse et Tello. En V. Roux (Ed.). Cornaline de l'Inde. Des practiques techniques de Cambay aux techno-systèmes de l'Indus (pp. 473-501). Paris: Éditions de la Maison des Sciences de l'Homme.

Jean-Marie, M.-L. (1999). Tombes et nécropoles de Mari: Mission archéologique de Mari V. Beirut: Institut Français d'archéologie du Proche-Orient.

Jiménez Ávila, J. (Ed.). (2017). Sidereum Ana III. El Río Guadiana y Tartessos. Mérida: Consorcio Ciudad Monumental Histórico-Artística y Arqueológica de Mérida.

Karagheorgis, V. (1974). Excavations at Kition, I. The Tombs. Nicosia: Department of Antiquities of Cyprus.

Lillios, K. (1999). Objects of Memory: The Ethnography and Archaeology of Heirlooms. Journal of Archaeological Method and Theory, 6(3), 235-262. DOI: https://doi. org/10.1023/A:1021999319447

López Amador, J. J. y Ruiz Gil, J. A. (2010). Las ofrendas del santuario púnico-gaditano de La Algaida (Sanlúcar de Barrameda). En M. Mata Almonte (Ed.). Cuaternario y Arqueología: Homenaje a Francisco Giles Pacheco (pp. 271-281). Cádiz: Diputación Provincial de Cádiz.

Lorrio, A. (2008). Qurénima. El Bronce Final del Sureste de la Península Ibérica. Madrid: Real Academia de la Historia.

Madeira, J., Gonçalves, J. L. M., Raposo, L. y Parreira, R. (1972). Achados da Idade do Bronze no Monte da Pena (Barro/Torres Vedras): Notícia Prévia. O Arqueólogo Português, III(6), 207-212.
Maluquer de Motes, J. (1983). El Santuario Protohistórico de Zalamea de la Serena, Badajoz. II, 1981-1983. Barcelona: Universidad de Barcelona.

Martín de la Cruz, J. C. (Coord.). (2004). Colgantes y cuentas de cornalina procedentes de Andalucía Occidental. Revista de Prehistoria, 3, 7-47.

Martín de la Cruz, J. C. (2008). El valle medio del Guadalquivir. En S. Celestino, N. Rafel y X.-L.Armada (Eds.). Contacto cultural entre el Mediterráneo y el Atlántico (siglos XII-VIII ane). La precolonización a debate (pp. 289-300). Madrid: Consejo Superior de Investigaciones Científicas.

Martín de la Cruz, J. C. y Vera Rodríguez, J. C. (2004). Discusión y valoración. Revista de Prehistoria, 3, 16-18.

Martín de la Cruz, J. C., Vera Rodríguez, J. C., Gavilán Cevallos, B. y Perlines Benito, M. (2005). Un colgante de cornalina de manufactura oriental procedente de la provincia de Córdoba. En S. Celestino Pérez y J. Jiménez Ávila (Eds.). El Período Orientalizante (pp. 503-509). Madrid: Consejo Superior de Investigaciones Científicas.

Martínez Mira, I. y Vilaplana Ortego, E. (2014). Cuentas de collar de La Fonteta (Guardamar, Alicante) y La Peña Negra (Crevillente, Alicante): descripción y análisis instrumental. En A. González Prats (Coord.). La Fonteta-2. Estudio de los materiales arqueológicos hallados en la colonia fenicia de la actual desembocadura del rio Segura (Guardamar, Alicante) (pp. 848-931). Alicante: Universidad de Alicante.

Mata Carriazo, J. (1973). Tartessos y El Carambolo. Investigaciones arqueológicas sobre la protohistoria de la Baja Andalucía. Madrid: Ministerio de Educación y Ciencia.

Mataloto, R. (2012). Os Senhores e as Serras: o final da Idade do Bronze no Alentejo Central. En J. Jiménez Ávila (Coord.). Sidereum Ana II. El río Guadiana en el Bronce Final (pp. 185-213). Madrid: Consejo Superior de Investigaciones Científicas.

Mazar, A. (2004). The Family Tomb n.l at the Northern Cemetery of Achziv (10 th $-6^{\text {th }}$ centuries). Cuadernos de Arqueología Mediterránea, 10. Barcelona: Universidad Pompeu Fabra.

McGovern, P. (1986). Late Bronze Age Palestinian Pendants: Innovation in a Cosmopolitan Age. Sheffield: American Schools of Oriental Research.

Menéndez Menéndez, A., Sanabria Murillo, D., Sánchez Hidalgo, F., Gibello Bravo, V. M. y Jiménez Ávila, J. (2013). La necrópolis orientalizante de Valdelagrulla (Medellín, Badajoz). Datos preliminares. En J. Jiménez Ávila, M. Bustamante y M. García Cabezas (Eds.). Actas del VI Encuentro de Arqueología del Suroeste Peninsular (pp. 999-1029). Villafranca de los Barrios: Ayuntamiento de Villafranca de los Barrios.

Merrillees, R. S. (1962). Opium Trade in the Bronze Age Levant. Antiquity, 36(144), 287-292. DOI: https://doi. org/10.1017/S0003598X00036814 
van de Mieroop, M. (2007). The Eastern Mediterranean in the Age of Ramesses II. DOI: http://dx.doi. org/10.1002/9780470696644

Molina Fajardo, F., Ruiz Fernández, A. y Huertas Jiménez, C. (1982). Almuñécar en la Antigüedad. La necrópolis fenicio-púnica de Puente de Noy. Granada: Caja de Ahorros de Granada.

Morricone, L. (1965-1966). Eleona e Langada: sepolcreti della Tarda Età del Bronzo a Coo. Annuario della Scuola archeologica di Atene e delle missioni italiane in Oriente, 43, 5-311.

Müller-Winckler, C. (1987). Die Ägyptischen ObjektAmulette. Göttingen: Vandenhoeck y Ruprecht

Padró, J. (1980-1985). Egyptian-Type Documents from the Mediterranean Littoral of the Iberian Peninsula before the Roman Conquest. 3 volumes. Leiden: Brill.

Padró, J. (1995). New Egyptian-Type Documents from the Mediterranean Littoral of the Iberian Peninsula before the Roman Conquest. Montpellier: Université Paul Valéry.

Perdigones, L.; Muñoz, A. y Pisano, G. (1990). La necrópolis fenicio-púnica de Cádiz. Roma: Universitá degli Studi di Roma.

Ponce, M. A. (2012). O Bronze Final na Península de Lisboa: o caso do Cabeço de Alcaínça na transição entre o 2. ${ }^{\circ}$ e o $1 .^{\circ}$ milénio A.C. (Tesis de Máster). Universidad de Lisboa. Lisboa. Recuperado de: http://repositorio.ul.pt/ handle/10451/9936

Quillard, B. (1973). Les étuis porte-amulettes carthaginois. Karthago, 16, 5-32.

Pereiro, T. do, Mataloto, R. y Borges, N. (2017). Alentejo, a Sul de Beja: a necrópole sidérica da Quinta do Estácio 6. En J. Jiménez Ávila (Ed.). Sidereum Ana III. El Río Guadiana y Tartessos (pp. 303-331). Mérida: Consorcio Ciudad Monumental Histórico-Artística e Arqueológica de Mérida.

Phillips, J. (2008). Aegyptiaca on the Island of Crete in Their Chronological Context: A Critical Review. Viena: Verlag der Österreichischen Akademie der Wissenschaften.

Reade, J. E. (1979). Early Etched Beads and the IndusMesopotamia Trade. Londres: British Museum.

Rigaud, S., Serrand, N. y Guilaine, J. (2017). Les parures des premières sociétés du Néolithique précéramique de Chypre: apport des gisements de Klimonas et de Shillourokambos. En J.-D. Vigne, F. Briois y M. Tengberg (Dirs.). Nouvelles données sur les débuts du Néolithique à Chypre (pp. 183198). Paris: Société Préhistorique Française.

Roux, V. (Ed.) (2000). Cornaline de l'Inde. Des practiques techniques de Cambay aux techno-systèmes de l'Indus.Paris: Éditions de la Maison des Sciences de l'Homme.

Roux, V. y Matarasso, P. (1999). Les perles de cornaline harappéennes: données ethno-archéologiques. En A. Caubet (Dir.). Cornaline et pierres précieuses. La Mediterrannée, de l'Antiquité à l'Islam (pp. 139-174). Paris: Réunion des Musées Nationaux.
Ruano Ruiz, E., Moreno, R. y Pellús, P. (1996). Los collares de La Algaida: ofrendas a un santuario gaditano. Boletín de la Asociación Española de Amigos de la Arqueología, 36, 107-133.

Ruiz Gil, J. A. y López Amador, J. J. (2004). Las piezas de la cabaña de Pocito Chico en su contexto (Puerto de Santa María, Cádiz). Revista de Prehistoria, 3, 11-14.

Ruiz Mata, D., Pérez Pérez, C. y Martín de la Cruz, J. C. (2004). Colgante procedente del yacimiento de la Sierra de San Cristóbal (Puerto de Santa María, Cádiz). Revista de Prehistoria, 3, 10-11.

Sánchez Romero, A. y Martín de la Cruz, J. C. (2004). Colgante procedente de Córdoba (Castro del Río, Córdoba). Revista de Prehistoria, 3, 9-10.

Schubart, H. y Niemeyer, H. G. (1976). Trayamar. Los hipogeos fenicios y el asentamiento en la desembocadura del rio Algarrobo. Madrid: Ministerio de Educación y Ciencia.

Soares, A. M. (2005). Os povoados do Bronze Final do Sudoeste na margem esquerda portuguesa do Guadiana: novos dados sobre a cerâmica de ornatos brunidos. Revista Portuguesa de Arqueologia, 8(1), 111-145.

Soares, A. M. y Martins, J. (2010). A cronologia absoluta para o Castro dos Ratinhos: Datas de Radiocarbono. En L. Berrocal-Rangel y A. C. Silva (Dirs.). O Castro dos Ratinhos (Barragem do Alqueva, Moura). Escavações num povoado proto-histórico do Guadiana, 2004-2007 (pp. 409-414). Lisboa: Museu Nacional de Arqueologia.

Soares, R. (2012): A Arrábida no Bronze Final. A paisagem e o homem. (Tesis de Máster). Universidad de Lisboa. Lisboa. Recuperado de: http://repositorio.ul.pt/handle/10451/9928

Soares, R. M., Baptista, L., Pinheiro, R., Oliveira, L., Rodrigues, Z. y Vale, N. (2017). A necrópole da I Idade do Ferro do Monte do Bolor 1-2 (Sao Brissos, Beja). En J. Jiménez Ávila (Ed.). Sidereum Ana III. El Río Guadiana $y$ Tartessos (pp. 263-302). Mérida: Consorcio Ciudad Monumental Histórico-Artística y Arqueológica de Mérida.

Torres Ortiz, M. (2008). Los «tiempos» de la precolonización. En S. Celestino, N. Rafel y X.-L. Armada (Eds.). Contacto cultural entre el Mediterráneo y el Atlántico (siglos XIIVIII ane). La precolonización a debate (pp. 59-92). Madrid: Consejo Superior de Investigaciones Científicas.

Vagnetti, L. (1982). L'Egeo, la Calabria e lámbiente tirrenico nel tardo II millennio. En G. Maddoli (Ed.). Temesa e il suo territorio (pp. 167-174). Taranto: Istituto per la Storia e la Archeologia della Magna Grecia.

Vera Rodríguez, J. C. (2004). Colgante procedente de los Castillejos de la Granjuela (Córdoba). Revista de Prehistoria, 3, 8-9.

Vilaça, R. (1995). Aspectos do Povoamento da Beira Interior (Centro e Sul) nos Finais da Idade do Bronze. 2 Volumes. Trabalhos de Arqueologia, 9. Lisboa: Instituto Português do Património Arquitectónico e Arqueológico.

Vilaça, R. (2008). Reflexões em torno da «presença mediterrânea» no Centro do território português, na charneira do Bronze para o Ferro. En S. Celestino, N. Rafel y X.-L. 
Armada (Eds.). Contacto cultural entre el Mediterráneo y el Atlántico (siglos XII-VIII ane). La precolonización a debate (pp. 371-401). Madrid: Consejo Superior de Investigaciones Científicas.

Vives y Escudero, A. (1917). Estudio de Arqueología Cartaginesa. La necrópolis de Ibiza. Madrid: Junta para la Ampliación de Estudios e Investigaciones Científicas.

Wartke, R.-S. (1999). Objets de parure de la tombe 45 à Assour. En A. Caubet (Dir.). Cornaline et pierres précieuses.
La Mediterrannée, de l'Antiquité à l'Islam (pp. 317-340). Paris: Réunion des Musées Nationaux.

Wilkie, N. (2000-2001). Stone Beads and Sealstones from the Mycenaean Tholos Tomb at Nichoria, Greece. BEADS: Journal of the Society of Bead Researchers, 12-13, 7-16. Recuperado de: https://surface.syr.edu/beads/vol12/iss 1/5

Xia, N. (2014). Ancient Egyptian Beads. Berlin-Heidelberg: Springer. DOI: http://dx.doi.org/10.1007/978-3-642-54868-0 